\title{
Ground motion estimation during 25th April 2015 Nepal earthquake
}

\author{
J. Dhanya ${ }^{1} \cdot{\text { Maheshreddy } \operatorname{Gade}^{1} \cdot \text { S. T. G. Raghukanth }}^{1}$
}

Received: 28 July 2015/ Accepted: 16 March 2016/Published online: 30 March 2016

(C) Akadémiai Kiadó 2016

\begin{abstract}
In the absence of an array of strong motion records, numerical and empirical methods are used to estimate the ground motion during 25th April 2015 Nepal earthquake. Spectral finite element method is used to simulate low frequency displacements. First, the simulated ground displacement is compared with the recorded data at Kathmandu. The good agreement between the comparisons validates the input source and medium parameters. The spatial variation of ground displacement is depicted through peak ground displacement and Ground residual displacement (GRD) contours near the epicentral region. The maximum GRD is of the order of $0.6 \mathrm{~m}$ in east-west, $1.8 \mathrm{~m}$ in north-south and $0.6 \mathrm{~m}$ in vertical $(Z)$ direction respectively. Stochastic finite fault seismological model is used to simulate acceleration time histories. First, the seismological model is calibrated for the region with the available strong ground motion records at Kathmandu. The estimated stress drop for main-event and aftershocks lie in between 50 and 95 bars. Acceleration time histories are simulated at several stations near the epicentral region. Peak ground acceleration (PGA) and spectral acceleration (Sa) contour maps are provided. The estimated PGA near the epicentral region varies from 0.3 to $0.05 \mathrm{~g}$. Another estimate of PGA for the main event is obtained from damage reports. The estimated PGA from simulations and damage reports are observed to be consistent with each other. The average amplification in the Indo-Gangetic plain is estimated to be in the order of 2-6. The simulated results from the study can be used as the basis for the possible ground motion behaviour for a future earthquake of comparable magnitude in the Himalayan region.
\end{abstract}

Keywords Ground motion · Topography · Seismological model · PGA-MMI

S. T. G. Raghukanth

raghukanth@iitm.ac.in

1 Department of Civil Engineering, Indian Institute of Technology- Madras, Chennai 600036, India 


\section{Introduction}

Nepal with Kathmandu $\left(27.7^{\circ} \mathrm{N}, 85.33^{\circ} \mathrm{E}\right)$ as capital lies between latitudes $26^{\circ}$ and $31^{\circ} \mathrm{N}$, and longitudes $80^{\circ}$ and $89^{\circ} \mathrm{E}$ with an area of $147,181 \mathrm{~km}^{2}$ in the Himalayan Mountains. The population in Nepal has increased tremendously over the last decade leading to urbanization, unplanned construction practices etc. According to the national census in 2011 by the Nepal Central Bureau of Statistics, the total population in Nepal is around 27 million which is about $14.44 \%$ growth from the last census of 2001 (Central Bureau of Statistics of Nepal: National Population and Housing Census 2011). Kathmandu is the most densely populated district in Nepal with population accounted to be around $6.58 \%$ of the total population as per the 2011 census. It should be noted that Nepal lies in Himalaya, which is identified as zone of high seismic hazard (Zone IV and V) by the Indian standard code of practice for earthquake resistant design of structures- IS 1893 (2002). Probabilistic seismic hazard map of India prepared by National Disaster Management Authority (NDMA 2011) assessed the PGA at Kathmandu to be around $0.35 \mathrm{~g}$ with $2 \%$ probability of exceedence in 50 years at A-type rock level. The region has suffered many earthquakes in the past, the 1934 Nepal-Bihar earthquake with moment magnitude $\left(M_{w}\right) 8.1$ being the most devastating one. The main cause of severe damage during the event is reported to be due to extensive liquefaction of ground (Dunn et al. 1939). The recent, 25 April 2015 Nepal earthquake $\left(M_{w} 7.86\right)$ has caused severe damage across the region. The main event epicenter lies at $28.147^{\circ} \mathrm{N}$ and $84.708^{\circ} \mathrm{E}$. Several moderate to strong after-shocks followed the main- event. The event triggered many landslides and also huge structural damages in the region causing a death toll of over 8000 people and injuries to more than 19,000 people. Kathmandu, Bhaktapur, Nuwakot, Sindhupalchok, Dhading and Gorkha are highly affected by this event. Significant damage is observed in approximately 50-60 year old unreinforced masonry buildings because of inadequate lateral strength as reported by many field investigations that followed the event (www.nicee.org/nepaleq/nepal.html). This event brought about a major economic loss as much as $\$ 10$ billion according to Nepal government. It is estimated that more than 700,000 houses and other structures are destroyed, which includes a dozen historical sites as well. The losses account for at least $25 \%$ of Nepal's Gross Domestic Product (GDP), with very low insurance penetration in the region. The cost of rebuilding could exceed $\$ 5$ billion by the estimates of Information Handling Services (IHS)

The damage during 2015 Nepal earthquake is mainly due to strong-near source ground motions and subsequent surface ruptures. These surface characteristics during an earthquake can be understood from the ground motion data near the source. The information from these ground motion data like amplitude, duration, frequency content, etc. also aids engineers in understanding the cause of structural damage. The Nepal-Himalayan region being critical due to frequent earthquakes has several seismic networks like Programme for Excellence in Strong Motion Studies (PESMOS) (http://www.pesmos.in/), National Seismic Network- Nepal (http://www.seismonepal.gov.np/) etc. However, the only strong motion record available for the main-event and for following aftershocks is at Kathmandu city maintained by USGS. The peak horizontal acceleration from the recording is $0.14 \mathrm{~g}$ for the main-event. Due to unavailability of ground motion array data, analytical approaches can be used to obtain the ground motion time histories. These models have been successfully used in estimating the ground motion of past earthquakes (Boore 2009; Raghukanth et al. 2012). The input parameters required, such as regional velocity profile, quality factor and ground attenuation for the Himalayan region are available in the 
literature (Yu et al. 1995; Singh et al. 2004). Surface level cracks and permanent displacements are observed in the epicentral region for this earthquake. These near field effects are very sensitive to faulting mechanism and direction of rupture propagation. Numerical and analytical techniques based on 3D elastic wave propagation can be used efficiently to explain these near field effects. In the present study, Spectral Finite Element Method (SPECFEM) is used to estimate the ground displacement time histories near the epicentral region. Peak ground displacement (PGD) and Ground residual displacement (GRD) contour maps are estimated near the epicentral region to understand the near field source characteristics. The numerical models are not efficient in capturing high frequency accelerations. Hence, stochastic finite fault seismological model is employed for the same. The source specific parameter stress drop $(\Delta \sigma)$ and site-specific parameter kappa $(\kappa)$ are first calibrated for stochastic finite fault approach of Boore (2009) using the strong motion records available at Kathmandu. The estimated parameters are further used to estimate acceleration time histories at various stations and PGA contour maps near the epicentral region. Another approach to determine PGA is through damage reports. The Modified Mercalli Intensity (MMI) values is estimated based on the intensity of the damage reported by various field investigations. These MMI values can give information regarding intensity of ground shaking. Several empirical equations between PGA and MMI values are available in the literature (Iyengar and Raghukanth 2003; Wald et al. 1999). The empirical equation given by Iyengar and Raghukanth (2003) for India is used in this study to estimate the PGA values at various stations. The PGA values obtained from seismological model are compared with PGA from MMI to check for consistency.

\section{Tectonic setup of Nepal region}

Himalayan and Tibetan Plateau are formed from continental drift and subsequent collision between the Indian subcontinent and the Eurasian continent. This collision, which started in Paleogene time and continuing even today contribute to the tectonic features in

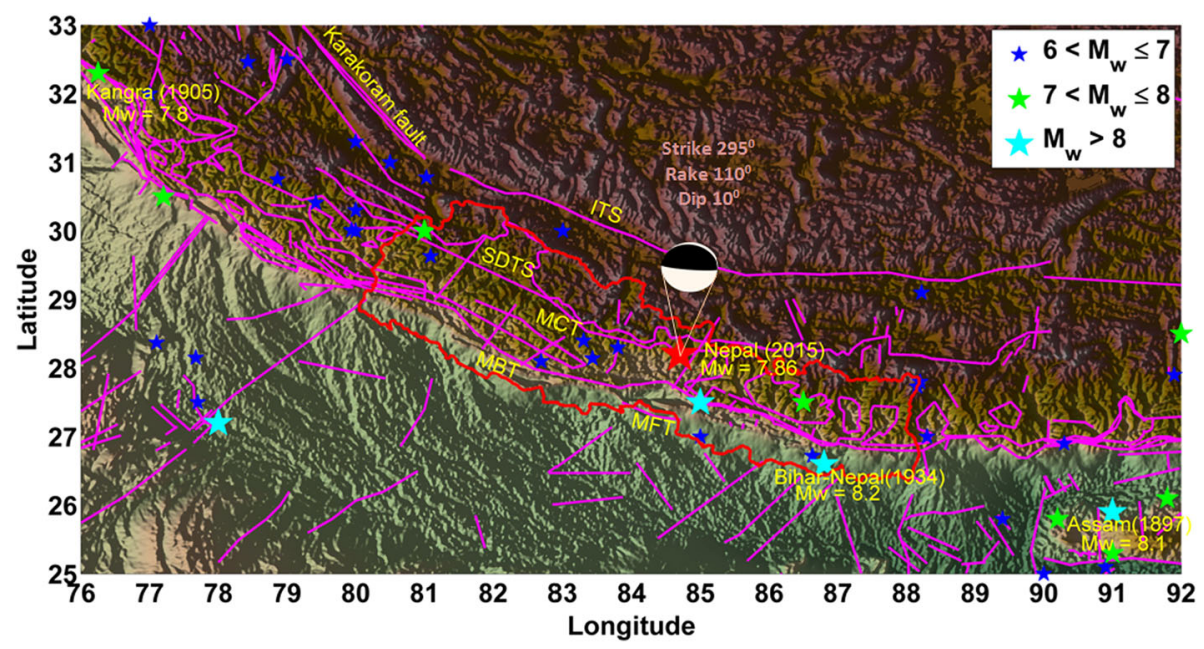

Fig. 1 Seismotectonic and seismicity map of Nepal Region. (MFT-Main Frontal Thrust, MCT-Main Central Thrust, MBT-Main Boundary Thrust, STDS-South Tibetan Detachment System, ITS Indo-Tsangpo suture) 
this region. The seismotectonic map of Nepal- Himalayan region along with seismicity is shown in Fig. 1. It is observed that major thrusting faults like Main Frontal Thrust (MFT), Main Central Thrust (MCT), Main Boundary Thrust (MBT), South Tibetan Detachment System (STDS) and Indo-Tsangpo Suture (ITS) passes through Himalayan arc dividing it into five major tectonic zones. These zones are namely from south to north Gangetic Plain, Sub-Himalayan (Siwalik) Zone, Lesser Himalayan Zone, Higher Himalayan Zone and Tibetian- Tethys Himalayan Zone respectively (Upreti 1999). Nepal occupies central sector of Himalayan arc and constitute these tectonic zones. The tectonic setting in Nepal is complex with MCT taking closed form in many parts of the country. Paleoseismic study by Lavé et al. (2005) discovered the evidences for a great earthquake at $\sim 1100$ A.D. $\left(\mathrm{M}_{\mathrm{w}} 8.8\right)$ in Nepal. The historic earthquake of 1255 A.D. caused mass destruction in the Kathmandu Valley, with damage index X in MMI scale (Chitrakar and Pandey 1986). The major earthquakes of 1260, 1408, 1681 and 1810 are also reported to have damaged many buildings and causing heavy loss of life (National Seismic Center (NSC)-Nepal). Another most devastating earthquake is the 1934 BiharNepal earthquake, where the damage is mostly due to extensive liquefaction (Dunn et al. 1939). The region between 1905 Kangra and 1934 Bihar-Nepal earthquake has not experienced any major earthquake since historic times. This section is indicated as seismic gap has high potential for future great earthquakes due to accumulated strain energy over the years (Khattri 1987; Bilham et al. 2001). Bilham et al. (2001) determined the seismic potential with convergence rate of the plate as $20 \mathrm{~mm} /$ year in central Himalaya by dividing the region into 10 sub-regions ( $\sim 220 \mathrm{~km}$ each), out of which 6 sub- regions which include a major portion of Nepal has a slip potential of at least $4 \mathrm{~m}$. From Fig. 1 it can be noted that the epicenter $\left(28.147^{\circ} \mathrm{N}\right.$ and $\left.84.708^{\circ} \mathrm{E}\right)$ of the $2015 \mathrm{Nepal}$ earthquake lies in this region. The focal mechanism solution by USGS indicates that the earthquake resulted as thrusting fault in MCT with strike angle $295^{\circ}$, dip $10^{\circ}$ and rake $110^{\circ}$. This earthquake has a shallow focal depth of $15 \mathrm{~km}$ from the surface. Figure 2 shows the distribution of some moderate to large aftershocks along with the slip distribution of main-event. A major aftershock occurred on 12 May 2015 is as high as $\mathrm{M}_{\mathrm{w}}$ 7.3. It can be seen that aftershocks are distributed in an area that is roughly $150 \mathrm{~km}$ long and $50 \mathrm{~km}$ wide, with the majority of the aftershocks located in the eastern part of the ruptured area.

\section{Source model- Nepal earthquake 25 April 2015}

The 2015 Nepal event triggered many broadband instruments across the globe by different networks like Global Seismic Network (GSN). Thus, there are many teleseismic broadband data available for the event. This data is used by various organizations to obtain the source parameters for the 25 April 2015 Nepal Earthquake. USGS used GSN broadband waveforms and selected 42 tele-seismic broadband $\mathrm{P}$ waveforms, 15 broadband SH waveforms, and 62 long period surface waves based on data quality and azimuthal distribution. The fault plane obtained upon inversion and error minimization is divided into 121 subfaults of size $20 \times 15 \mathrm{~km}$. Thus, estimated length of the fault is $220 \mathrm{~km}$ along the strike angle of $295^{\circ}$ and width of $165 \mathrm{~km}$ along the dip angle of $10^{\circ}$. The details of the slip model are summarized in Table 1 and the slip distribution is shown in Fig. 2. The hypocenter of the main-event is located at 170 and $82.5 \mathrm{~km}$ along strike and down dip direction respectively. From the slip distribution it can be observed 


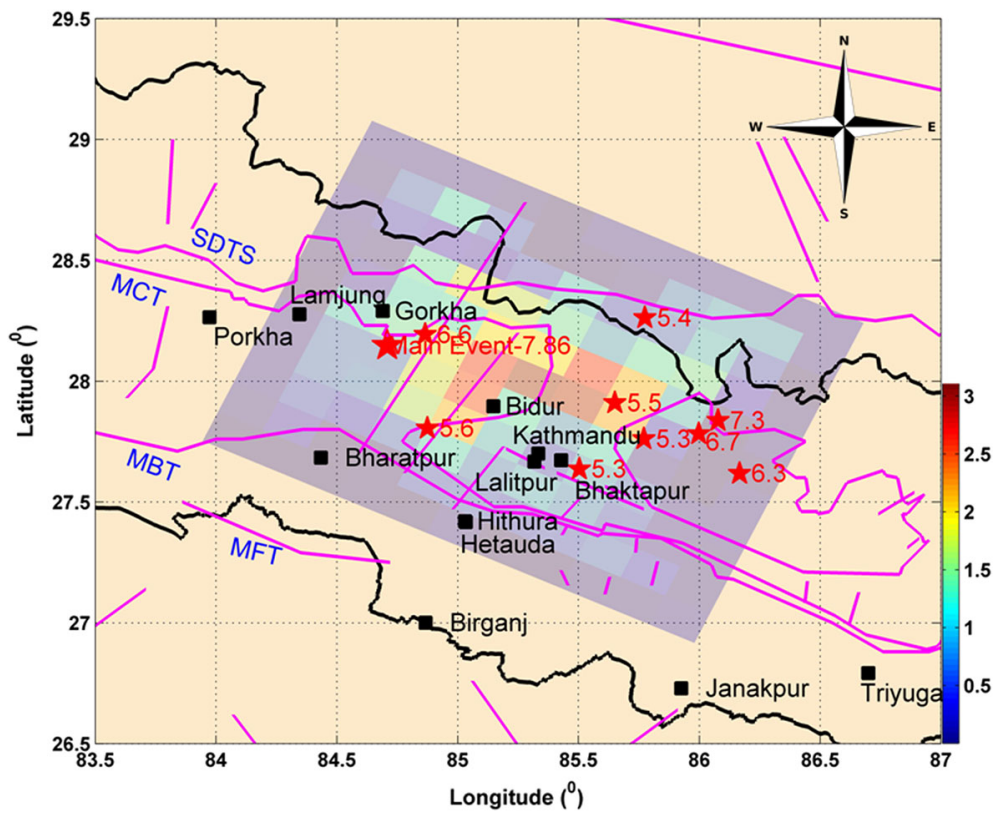

Fig. 2 Finite slip distribution (slip in $\mathrm{m}$ ) of main-shock and distribution of the epicenters of aftershocks that followed the $\mathrm{M}_{\mathrm{w}} 7.86$ main event

Table 1 USGS finite slip distribution for 25 April 2015 Nepal Earthquake

\begin{tabular}{ll}
\hline Size & \\
Length $(\mathrm{km})$ & 220 \\
Width $(\mathrm{km})$ & 165 \\
Mw & 7.86 \\
Mo (Nm) & $8.056 \mathrm{e}+20$ \\
Mechanism & \\
Strike $\left(^{\circ}\right)$ & 295 \\
Dip $\left(^{\circ}\right)$ & 10 \\
Rake $\left(^{\circ}\right)$ & 110 \\
Sub-fault & \\
Nx $\times$ Nz & $11 \times 11$ \\
Dx $(\mathrm{km})$ & 20 \\
Dz $(\mathrm{km})$ & 15 \\
\hline
\end{tabular}

that the maximum slip is in the order of $3.1 \mathrm{~m}$, at a radial distance of $60 \mathrm{~km}$ to the east of hypocenter. The time taken by the rupture to reach farthest point from hypocenter is $107.6 \mathrm{~s}$. The average rupture velocity used to calculate the rupture time is $2.12 \mathrm{~km} / \mathrm{s}$. Rise time, which is defined as the time taken by each subfault to rupture completely, varies from 1.6 to $12.8 \mathrm{~s}$. Many researchers have developed slip models for this event. The slip distributions reported by various organizations are almost similar in pattern as that of USGS. Hence, the distribution given in Fig. 2 is used in the present study for the main-event. 


\section{Strong motion data}

It should be noted that the earthquake characteristics and other information specific to the event can be better assessed from the strong motion records near the epicentral region. Strong motion records also provide an idea about local site condition. For the 2015 Nepal Earthquake strong motion records are available only at a station in Kathmandu. This strong motion data is provided by the Center for Engineering Strong Motion Data (CESMD) from the recordings of NetQuakes instrument (www.strongmotioncenter.org). The instrument is located at Kanti Path $\left(27.71^{\circ} \mathrm{N}, 85.315^{\circ} \mathrm{E}\right)$, Kathmandu (id: KATNP, USGS network). The strong motion recording of the instrument during the $2015 \mathrm{M}_{\mathrm{w}} 7.86$ Nepal Earthquake and the major aftershock of $M_{w} 7.3$ that followed is as shown in Fig. 3. The PGA for the mainevent is observed to be $0.139,0.144$ and $0.164 \mathrm{~g}$ in East-West $(\mathrm{E}-\mathrm{W})$, North-South $(\mathrm{N}-\mathrm{S})$ and vertical $(\mathrm{Z})$ directions respectively, and for the $\mathrm{M}_{\mathrm{w}}$ 7.3-aftershock the corresponding values are $0.072,0.087$ and $0.075 \mathrm{~g}$. The examination of the frequency content of the recorded data of the main-shock showed a strong influence of low frequency waves. The displacements obtained by double integration of the recorded acceleration time histories are also shown in Fig. 3. It can be noted that there is permanent displacement of the order of about $1 \mathrm{~m}$ in all three directions for the main event. This permanent displacement confirms the strong influence of source characteristics on ground motions. Due to unavailability of strong motion records other than that at KATNP, SPECFEM and stochastic finite fault model are used to simulate the displacement and acceleration time histories respectively at various stations in the epicentral region.

\section{SPECFEM}

The near-field ground displacements will be strongly influenced by the fault mechanism and direction of rupture propagation. Numerical techniques based on kinematic source models and elastic wave propagation approaches are very efficient in simulating low frequency displacements. These techniques are capable of modelling the source directivity effects on ground displacements. In the present study, SPECFEM3D Cartesian package, which is a collection of FORTRAN subroutines, available in https://geodynamics.org is used to simulate displacement time histories near the epicentral region.

Patera (1984) developed the Spectral Element Method (SEM) for computational fluid dynamics. Later, Komatitisch and Tromp (1999) applied this method for problems related to $3 \mathrm{D}$ seismic wave propagation. This method can efficiently handle surface topography. The local variation in material property can be incorporated to improve the accuracy of the simulations. For the simulations, the region is first discretized into nonoverlapping hexahedral elements. Each element is mapped to a reference cube using classical Jacobian matrix. Lagrange interpolants are assumed to represent the displacement field in each element. Unlike the traditional Finite element method, SPECFEM uses high-degree Lagrange interpolant to represent the basic functions for the displacement. The control points needed to define polynomial of order $n$ is $(n+1)^{3}$ Gauss-LobattoLegendre (GLL) points per element. Once the discretization of the region is completed, the global system of equation to be solved by assembling contributions from individual elements can be written as:

$$
\mathbf{M} \ddot{\mathrm{u}}+\mathbf{C} \dot{\mathrm{u}}+\mathbf{K} \mathrm{u}=\mathrm{F}
$$



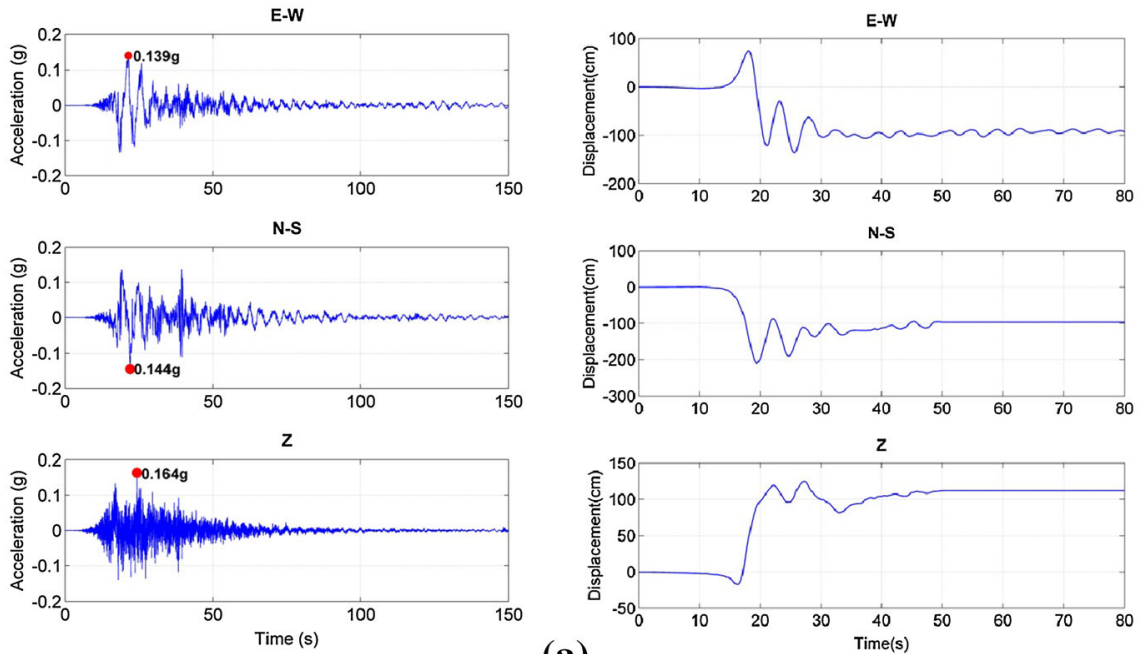

(a)
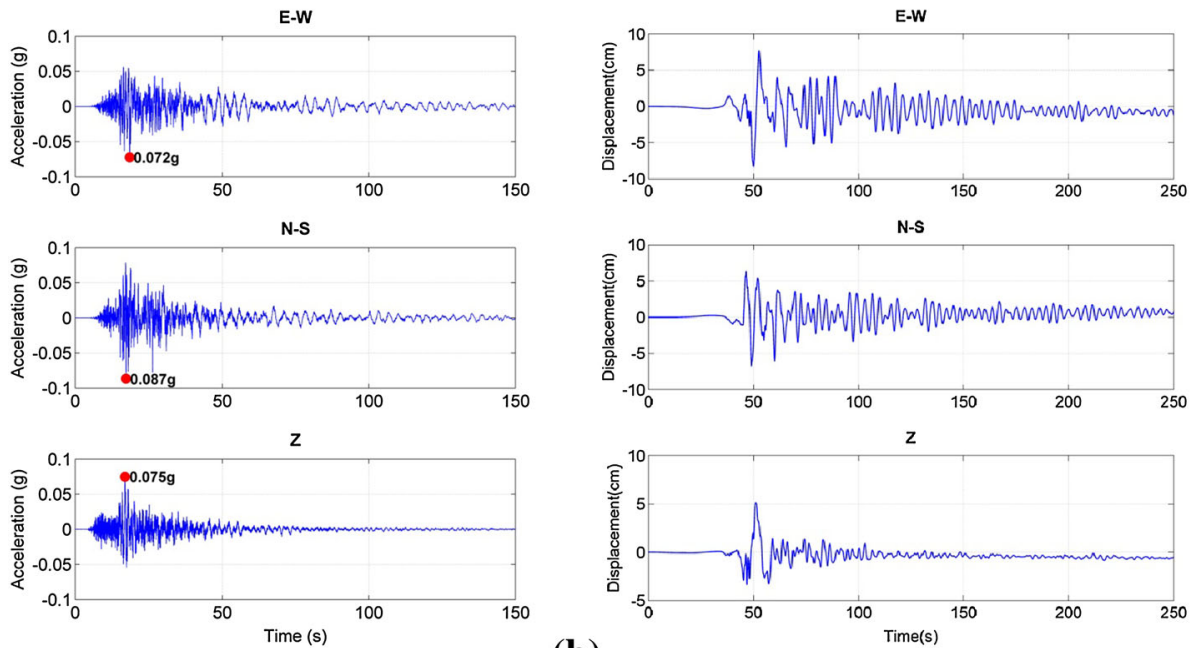

(b)

Fig. 3 Recorded strong motion acceleration and displacement time history respectively at Kathmandu (a) main event $\mathrm{M}_{\mathrm{w}}-7.86$ (b) After shock $\mathrm{M}_{\mathrm{w}}-7.3$

where $\mathbf{u}$ the global displacement vector, $\mathbf{M}$ the global mass matrix, $\mathbf{C}$ the global absorbing boundary matrix, $\mathbf{K}$ the global stiffness matrix and $\mathbf{F}$ the source term. Explicit expressions for $\mathbf{M}, \mathbf{C}, \mathbf{K}$, and $\mathbf{F}$ matrices at elemental level and further construction of these matrices at global level are available in the article of Komatitsch and Tromp (1999). The main advantage of SPECFEM is that it reduces the computational complexity by rendering mass matrix $\mathbf{M}$ diagonal, using Lagrange polynomial in conjunction with GLL quadrature. An explicit second order finite difference scheme is used to march forward the Eq. 1 in time. The stability of the scheme depends on the Courant stability condition. In the present case, maintaining the Courant number less than 0.3 avoids undesirable error accumulation and shooting up of values during forward time marching (Komatitsch et al. 2015). 


\subsection{Simulation of ground displacement}

The simulations for the present study is performed by implementing the SPECFEM3D package in Rocks6.1 (Emerald Boa) Cluster with AMD opteron (TM) processor installed with Centos6.3 (OS), the machine has two nodes with 32 processors per node. The simulation is executed using parallel programming based on message-passing interface (MPI). The first step in SPECFEM is to generate mesh of the required area. A regional mesh of size is $800 \times 800 \times 80 \mathrm{~km}$ is selected to avoid the effect of any undesirable reflections from absorbing boundaries on ground motions. The mesh covers the region from $24^{\circ} \mathrm{E}$ to $31^{\circ} \mathrm{E}$ latitude and $82^{\circ} \mathrm{N}$ to $89^{\circ} \mathrm{N}$ longitude. The topography and bathymetry model available at 1-min interval grid from the US National Oceanic and Atmospheric Administration (NOAA) as shown in Fig. 1 is smoothened and used as the surface elevation of the mesh (http://www.ngdc.noaa.gov/). The material property distribution along the depth is taken as that reported by Yu et al. (1995) for Himalayan region, given in Table 2. Non-overlapping hexahedral finite element mesh is used to discretize the region. The mesh characteristics of the present study is summarized in Table 3. The number of spectral elements at the surface in each direction is $240 \times 240$. The mesh is denser near the surface where the wave speed is low than at depth. Coarsening of the mesh with depth helps in retaining number of grid points per wavelength. Using coarser mesh with depth also reduces the memory requirement, thus the computational cost reduces. The quality of the distorted element from the regular hexahedral element is assured through limiting the skewness of the element. The skewness is the measured by evaluating the maximum deviation of the angle between the edges of the face from the right angle position. A skewness value of ' 0 ' corresponds to

Table 2 Regional velocity model (Yu et al. 1995)

\begin{tabular}{llllrr}
\hline Depth $(\mathrm{km})$ & $\mathrm{V}_{\mathrm{p}}(\mathrm{km} / \mathrm{s})$ & $\mathrm{V}_{\mathrm{s}}(\mathrm{km} / \mathrm{s})$ & Density $\left(\mathrm{g} / \mathrm{cm}^{3}\right)$ & $\mathrm{Q}_{\mathrm{P}}$ & $\mathrm{Qs}_{\mathrm{s}}$ \\
\hline $0-0.4$ & 3.5 & 2.00 & 1.80 & 50 & 25 \\
$0.4-1.0$ & 5.0 & 2.86 & 2.40 & 80 & 50 \\
$1.0-15.0$ & 5.2 & 2.97 & 2.60 & 4000 & 2000 \\
$15.0-30.0$ & 6.0 & 3.43 & 2.90 & 4000 & 2000 \\
$>30.0$ & 8.33 & 4.83 & 3.30 & 1000 & 500 \\
\hline
\end{tabular}

Table 3 Mesh characteristics

\begin{tabular}{ll}
\hline Characteristic & Value \\
\hline Dimension $\left(\mathrm{km}^{2}\right)$ & $800 \times 800$ \\
Depth $(\mathrm{km})$ & 80 \\
Type of element & Hexahedral \\
No: of spectral element on each side & $246 \times 246$ (top-surface) \\
Total no: of elements & $3.1 \times 10^{5}$ \\
Min size of element $\left(\mathrm{km}^{3}\right)$ & $3.34 \times 3.34 \times 0.4$ \\
Max size of element $\left(\mathrm{km}^{3}\right)$ & $13.4 \times 13.4 \times 10$ \\
No: of nodes & 20.8 million \\
Total degree of freedom & 62.4 million \\
Time step used for simulation & $0.0055 \mathrm{~s}$ \\
\hline
\end{tabular}



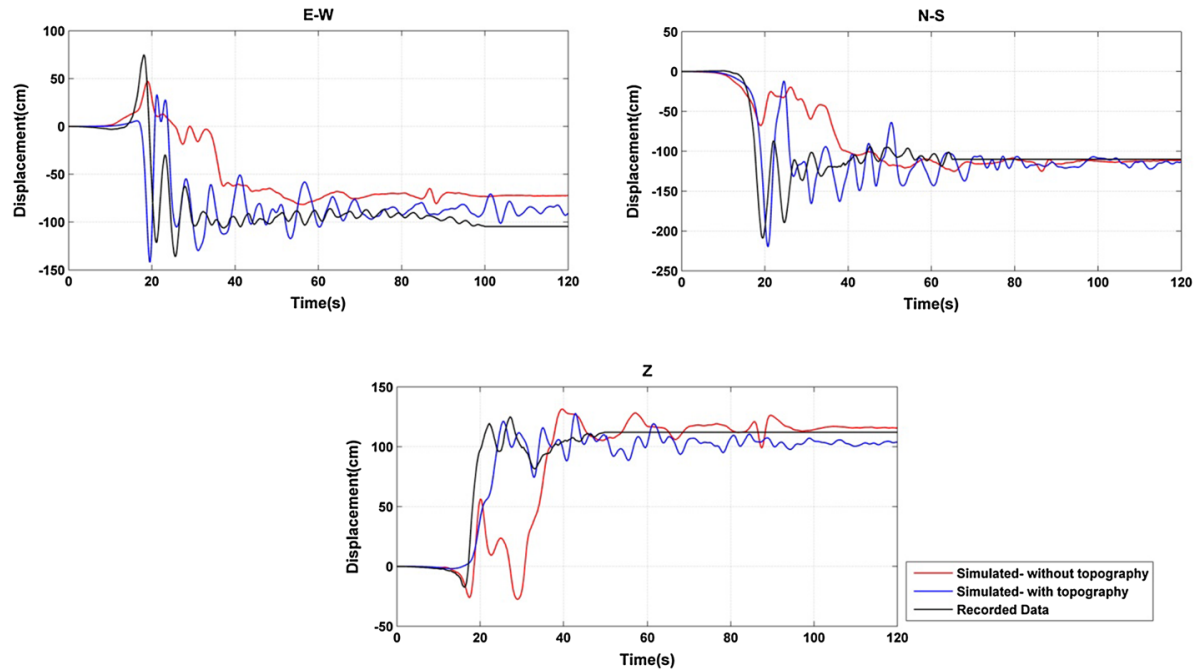

Fig. 4 Comparison of ground displacement time histories between SPECFEM and recorded data at Kathmandu

perfect hexahedron and ' 1 ' corresponds to bad mesh. In the present study, the skewness of the meshing is maintained less than 0.80 to ensure the mesh quality (Komatitsch et al. 2015). The minimum element size is $3.34 \times 3.34 \times 0.4 \mathrm{~km}$ and maximum $13.4 \times 13.4 \times 10 \mathrm{~km}$. The time step of $5.5 \mathrm{~ms}$ is selected such as to maintain Courant stability condition. The total number of processors used to handle the mesh is 25. The centroid moment tensor (CMT) solution reported by USGS for fault mechanism given in Fig. 2 is used to simulate the ground displacements. The calculation requires $7 \mathrm{~GB}$ of distributed memory. The total computational time taken to simulate displacements for $3 \mathrm{~min}$ is around $12 \mathrm{~h}$.

In-order to understand the effect of topography on ground displacement, the simulation is performed for both with and without topography. The material property of the topography layer is maintained same as that of the first layer property provided in Table 2 . The simulated displacements are first compared with the strong motion recording available at the KANTP station as illustrated in Fig. 4. It is very clear that the simulated results are able to capture the ground displacement behaviour exhibited by the recording. It should be noted that the simulated ground displacement time history with topography is able to capture the phase, PGD and GRD of the recorded data in all three directions better than that without topography. Thus, the modifications to the ground motion due to the surface undulations are taken care by the addition of topography. This simulation with topography is extended further to simulate the ground displacement time histories at various stations near the epicentral region as shown in Fig. 5. From the simulated time histories the maximum value of displacement is observed in Kodari as $127 \mathrm{~cm}$ in E-W $395.65 \mathrm{~cm}$ in $\mathrm{N}-\mathrm{S}$ and $80.64 \mathrm{~cm}$ in vertical (Z) direction respectively. It can be noted that the simulated ground displacement time histories at various stations differed in phase, peak and residual values. Hence, to understand the spatial variation of ground displacement, time histories can be simulated on a grid near the epicentral region. In the study, the displacement field is computed at a spacing of $2.3 \mathrm{~km}$ covering $350 \times 275 \mathrm{~km}$ near the epicentral region. The resultant contours of PGD in horizontal and vertical directions are shown in Fig. 6(a, b) respectively. It can be observed that the ground motions followed certain low frequency 

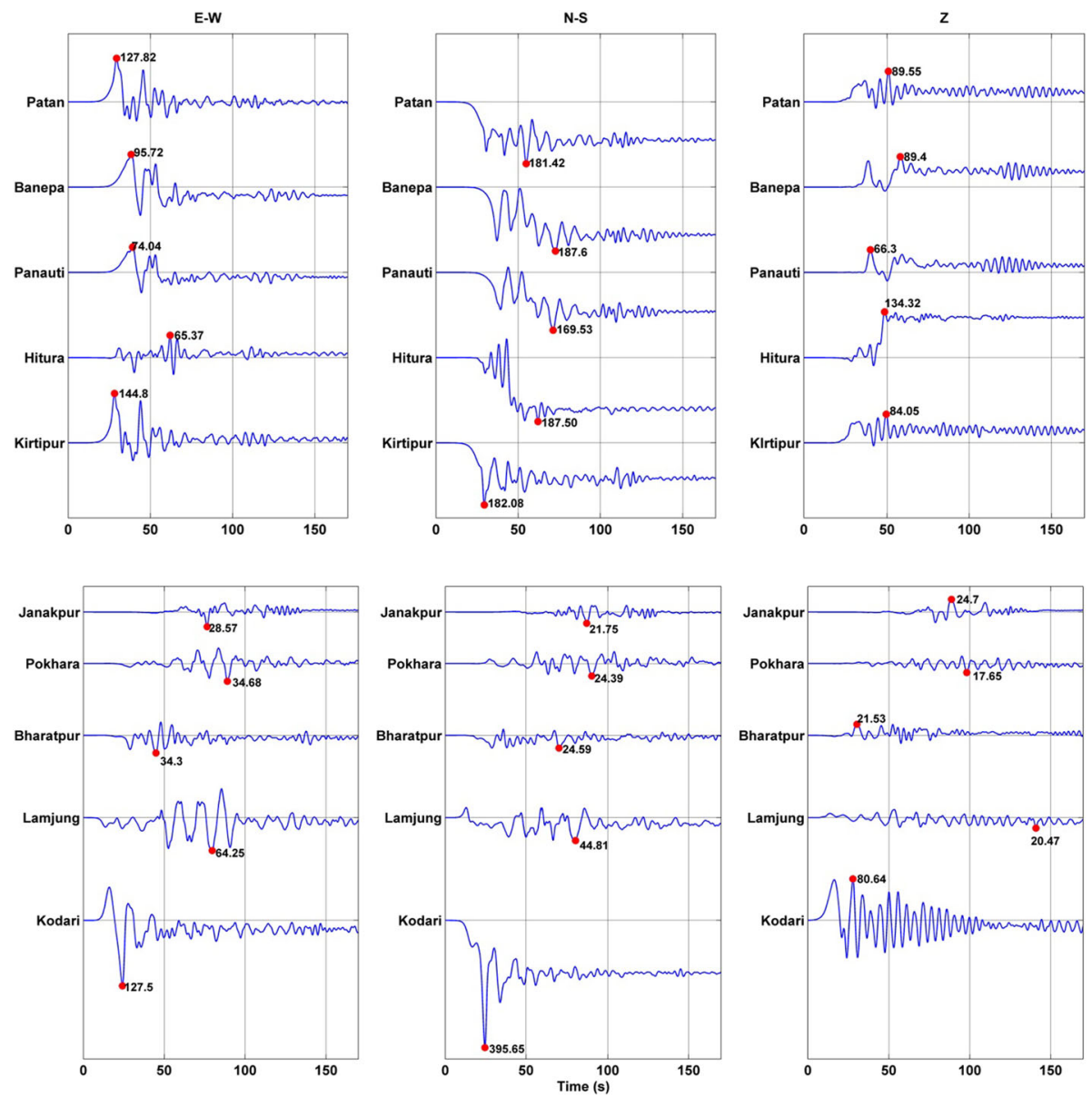

Fig. 5 Simulated ground displacement time histories (in $\mathrm{cm}$ ) using SPECFEM at various stations

characteristics like radiation patterns and rupture-directivity effects. The maximum PGD values in horizontal and vertical directions are $4 \mathrm{~m}$ and $1.6 \mathrm{~m}$ respectively. The maximum PGD value is observed, where the slip distribution is maximum over the fault plane and decreases towards the edge of the fault. Figures $7(\mathrm{a}-\mathrm{c})$ present the contours of GRD in the $\mathrm{N}-\mathrm{S}, \mathrm{E}-\mathrm{W}$, and $\mathrm{Z}$ directions. These static displacements decrease with an increase in epicentral distance. It can be observed from Fig. 7(b) that the entire region has moved towards the south. The maximum vertical displacement of $0.6 \mathrm{~m}$ is observed at the station Bidur. Since the top soil would behave in a nonlinear fashion, the large displacements in the linear model would hint at ground failures due to the high level of strains.

\section{Stochastic finite fault model}

The numerical method employed above is efficient in simulating low frequency ground displacement. On the other hand, these techniques have limited capability in simulation of high frequency accelerations required for engineering applications. In such situation, the 


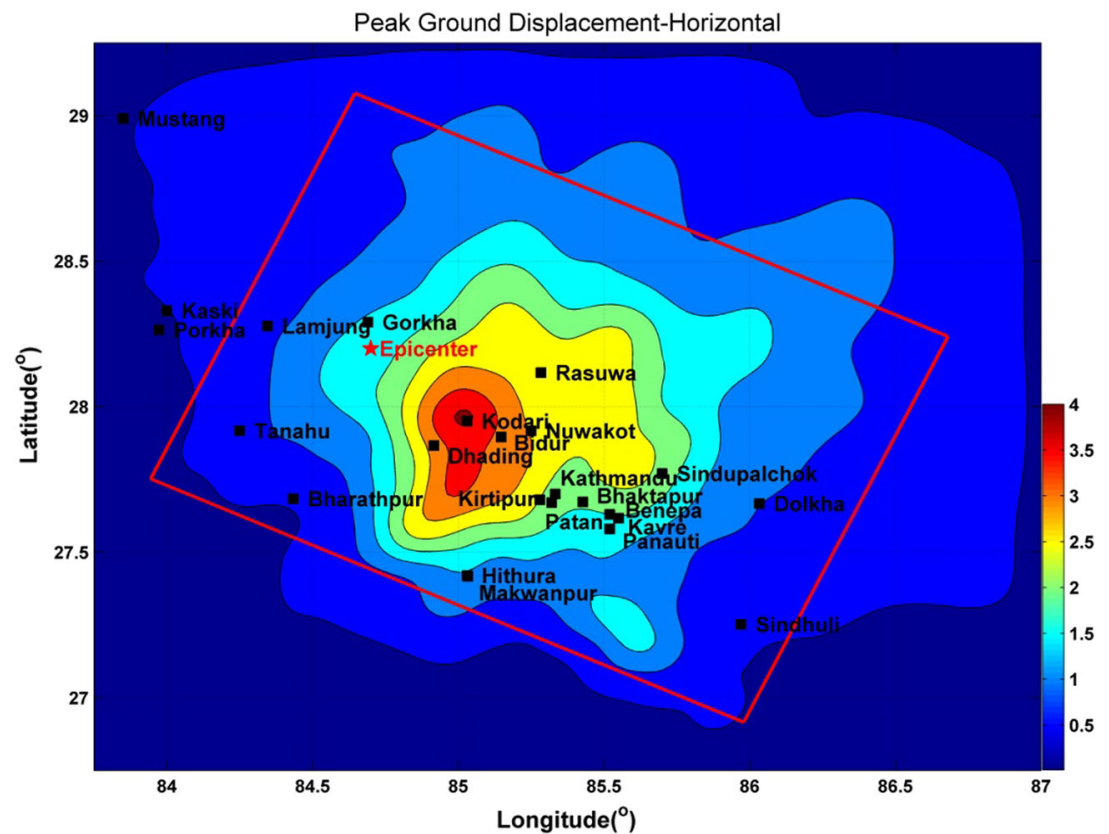

(a)

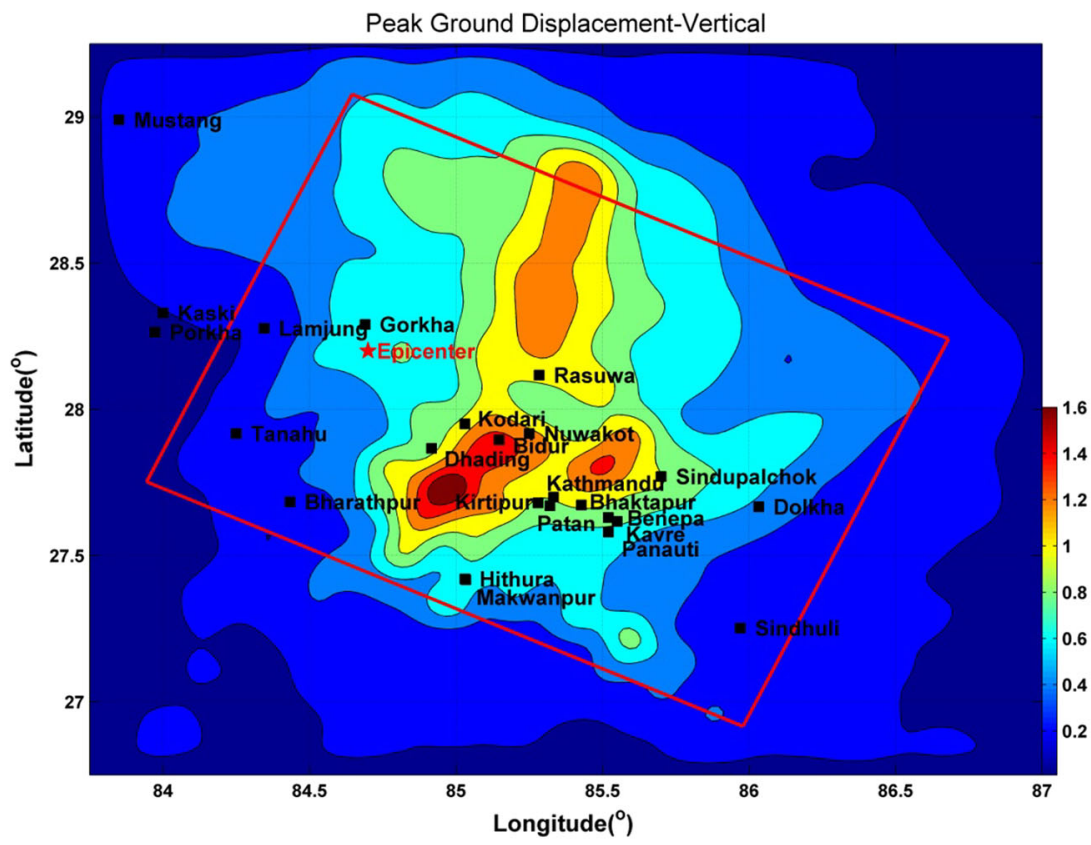

(b)

Fig. 6 Simulated PGD (m) at surface near the epicentral region a horizontal direction $\mathbf{b}$ vertical direction (the red rectangular box indicate the surface projection of fault plane) 


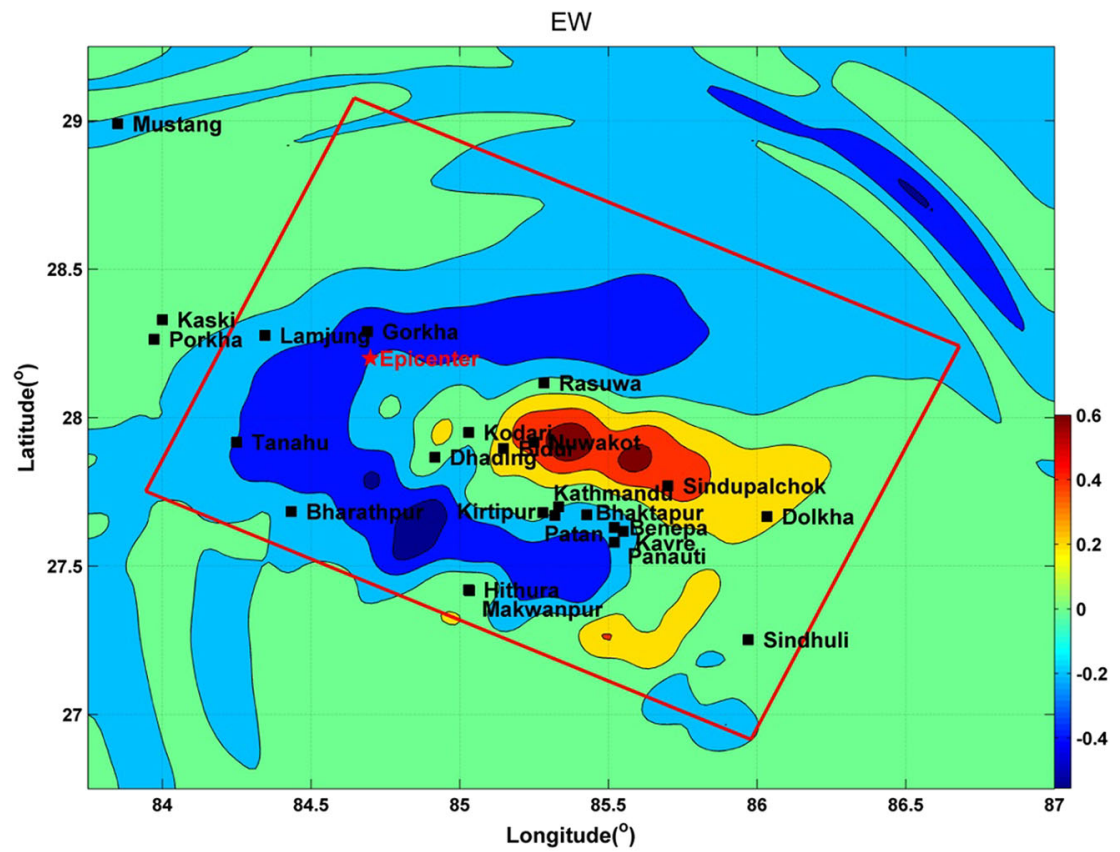

(a)

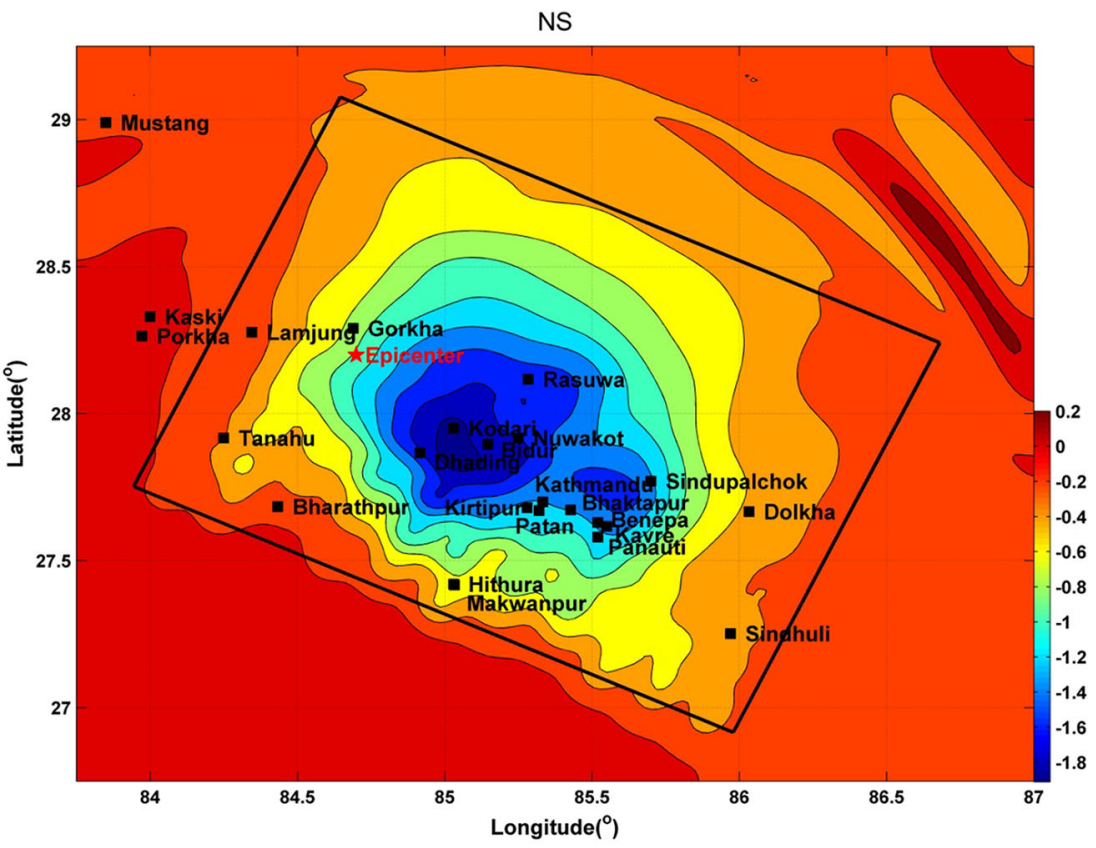

(b)

Fig. 7 Simulated GRD (m) at surface near the epicentral region a east-west (E-W) direction b north-south (N-S) direction c vertical $(\mathrm{Z})$ direction 


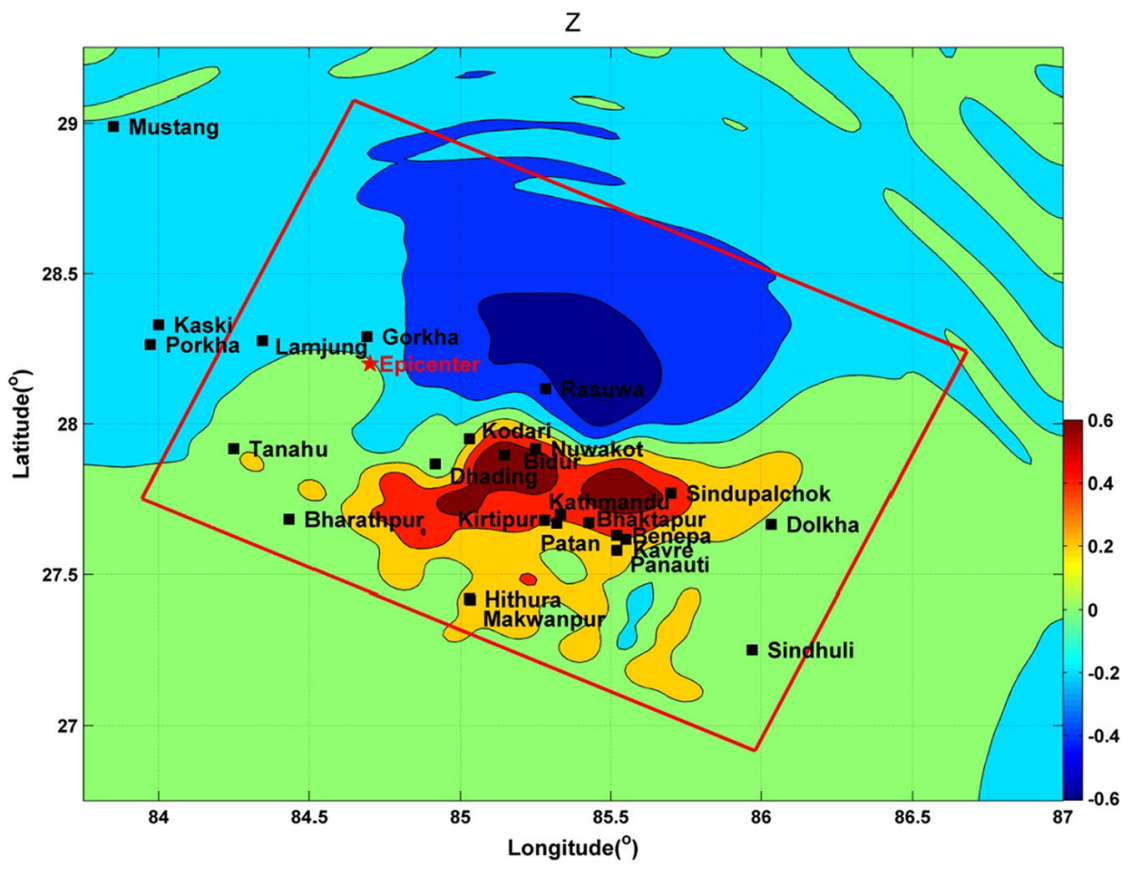

(c)

Fig. 7 continued

one-dimensional stochastic seismological model can be used as an alternative to estimate ground motion. In the present study, the stochastic finite fault approach of Boore (2009), which is an improved version of the methodology proposed by Motazedian and Atkinson (2005) is used to obtain the acceleration time history. The theory and application of stochastic finite fault models for estimating ground motion has been discussed in detail by Boore (2009). Raghukanth and Somala (2009), NDMA (2011) and Raghukanth et al. (2012), have discussed the application of this model for estimating ground motion in the Himalayan region of India in detail. A brief description of this method is given as follows. In this method, the rectangular fault plane is divided into $\mathrm{N}$ number of subfaults and each subfault is represented as a point source. The Fourier Amplitude Spectra (FAS) $[Y(r, f)]$ of ground motion due to the $j$ th subfault at a site is derived from the point source seismological model, expressed as:

$$
Y_{j}(r, f)=\frac{\left\langle R_{\theta \varphi}\right\rangle \sqrt{2}}{\rho V_{s}^{3}} G \exp \left[\frac{-\pi f r}{V_{s} Q(f)}\right] \frac{\pi f^{2} M_{0 j}}{\frac{1}{\sqrt{N}}+\frac{1}{H_{j}}\left(f / f_{0 j}\right)^{2}} F(f)
$$

where $\left\langle R_{\theta \varphi}\right\rangle$ is the radiation coefficient averaged over an appropriate range of azimuths and take-off angles. $V_{s}$ is the shear wave velocity and $\rho$ is the material density at the focal depth. In the above equation $Q(f)$ denotes quality factor of the medium, $F(f)$ is the site amplification function and $H_{j}$ is a scaling factor used for conserving the energy of highfrequency spectral level of sub-faults. The exponential term in the expression represents 
attenuation of the wave with distance. $M_{0 j}$, the moment of $j t h$ subfault is computed from the slip distribution as follows:

$$
M_{0 j}=\frac{M_{0} D_{j}}{\sum_{j=1}^{N} D_{j}}
$$

where $D_{j}$ is the average final slip acting on the $j$ th subfault and $M_{0}$ is the total seismic moment on the fault. The simulated time histories from this methodology strongly depend on subfault size. Hence, Motazedian and Atkinson (2005) introduced the concept of dynamic corner frequency $\left(f_{0 j}\right)$ expressed as:

$$
f_{0 j}=4.9 \times 10^{6}\left(N_{R j}\right)^{-1 / 3} V_{s}\left(\frac{\Delta \sigma}{M_{0} / N}\right)^{1 / 3}
$$

where $\Delta \sigma$ is stress drop, $\mathrm{N}$ is the total number of subfaults and $N_{R j}$ is the total number of ruptured subfaults by the time rupture reaches the $j t h$ subfault. In Eq. $2, H_{j}$ is scaling factor for $j$ th subfault, introduced by Atkinson et al. (2009), is expressed as:

$$
H_{j}=\left(N \frac{\sum_{f}\left(\frac{f^{2}}{1+\left(f / f_{o}\right)^{2}}\right)^{2}}{\sum_{f}\left(\frac{f^{2}}{1+\left(f / f_{o j}\right)^{2}}\right)^{2}}\right)^{1 / 2}
$$

where $f_{0}$ is the corner frequency at the end of the rupture. The concept of pulsing area is taken to account for the mechanism of earthquake rupture (Motazedian and Atkinson 2005). According to this number of active subfaults $\left(N_{R j}\right)$ increases from the time of initiation of rupture, but remain constant once fixed percentage of the total rupture area is reached. This parameter determines the number of active subfaults during the rupture of $j t h$ subfault.

The next step is to estimate the time histories from the FAS obtained from Eq. 2. This process involves three steps. First, a Gaussian white noise sample of length equal to the strong motion duration is assumed for each subfault. The sample length is expressed as:

$$
T=\left(1 / f_{o j}+0.05 r_{j}\right)
$$

where $r_{j}$ the distance from subfault to station. This sample is then windowed by multiplying with a suitable non-stationary modulating function. The simulated sample is Fourier transformed into frequency domain. This spectrum is normalized by the square-root of mean square amplitude spectrum and then multiplied by seismological source-path-site function $(Y(r, f)$ ) (Eq. 2). Finally, The resulting spectra are transformed back into time domain to obtain the sample ground motion accelerogram for each subfault. The final ground acceleration is obtained by summing up the simulated acceleration time histories of all subsets with the delay that accounts for the rupture velocity.

The model described is valid for any region only if various controlling parameters are selected suitably. The regional specific input parameters are quality factor $Q$, geometric attenuation $\mathrm{G}$, focal depth, orientation of fault plane, stress drop $(\Delta \sigma)$ and the site amplification function $F(f)$. The quality factor and geometric attenuation for a region can be determined by regression analysis if an array of recorded data is available. Such an array of recorded data is not present for the this event. Thus, these parameters are fixed for the present study based on the values calibrated for seismological model by various 
researchers in the past for the region. Thus, quality factor $\left(\mathrm{Q}=253 f^{0.8}\right)$ and geometrical attenuation developed by Singh et al. (2004) for Himalayan region is used. This geometrical attenuation term $\mathrm{G}$ can be expressed as:

$$
G= \begin{cases}\frac{1}{r}, & \text { for } r \leq 100 \mathrm{~km} \\ \frac{1}{10 \sqrt{r}}, & \text { for } r>100 \mathrm{~km}\end{cases}
$$

The geometric attenuation is proportional to $1 / \sqrt{ } \mathrm{r}$ at a distance greater than $100 \mathrm{~km}$ to take into account for the effect of energy carried by surface wave. Focal depth, orientation of fault plane and slip distribution are taken from the fault parameters reported by USGS as depicted in Fig. 2. The shear wave velocity and density at the focal depth are fixed as $3.6 \mathrm{~km} / \mathrm{s}$ and $2800 \mathrm{~kg} / \mathrm{m}^{3}$, respectively corresponding to bedrock (Singh et al. 2004). The S-wave radiation coefficient $\left(\left\langle R_{\theta \phi}\right\rangle\right)$ varies randomly with in a particular interval. Here, following Boore and Boatwright(1984) an average value of 0.55 is considered. Pulsing percentage has only limited sensitivity on ground motion. Thus, an average value between 25 and $75 \%$, i.e., $50 \%$ is used. The determination of site amplification, stress drop $(\Delta \sigma)$ and kappa $(k)$ of the particular event is as explained further.

\subsection{Site amplification}

The amplitude and frequency content of ground motion at the bedrock level are modified upon traversing through the local soil layers with respect to the layer properties. The three important layer properties that influence site amplification are shear wave velocity, density and material damping. These properties can be incorporated in Eq. 2. by the function $F(f)$ expressed as:

$$
F(f)=A(f) e^{-\pi \kappa f}
$$

where, $A(f)$ represents the site amplification due to propagation of earthquake wave from the bed rock level to surface level. It should be noted, that an extensive shear wave profile distribution data is not available for the region. Since such a record is not there one has to resort to alternate means to quantify site amplifications. The local soil effect is found to be stronger in horizontal components and week in vertical components (Nakamura, 1989). The studies on by Field and Jacob (1993) suggest that $\mathrm{H} / \mathrm{V}$ is an efficient tool to characterize site effects. This method is the simplest technique to model site effect, hence widely used. In obtaining seismic site response $(A(f))$ at a particular location, it is best suited to measure the ground motion at the site during the actual event. Hence, in this study the $\mathrm{H} / \mathrm{V}$ ratio obtained from the response spectra, estimated from strong motion recordings of Kathmandu, is used to account for $A(f)$. The corresponding $\mathrm{H} / \mathrm{V}$ ratio for main event and aftershocks along with the mean $\mathrm{H} / \mathrm{V}$ ratio are shown in Fig. 8. It can be observed that the predominant frequency of the recorded data at KANTP station varies from 0.1 to $0.5 \mathrm{~Hz}$, which is closer to the value of $0.6 \mathrm{~Hz}$ reported based on microtremor investigations by Paudiya et al. (2013). The exponential term in Eq. 8 is the attenuation or diminution to account for damping of high frequency in ground motions that might be due to source effect or site effect. Where $\kappa$ is the kappa factor to reduce the high-frequency amplitudes above some threshold frequency and characterizes the nearsurface attenuation. 


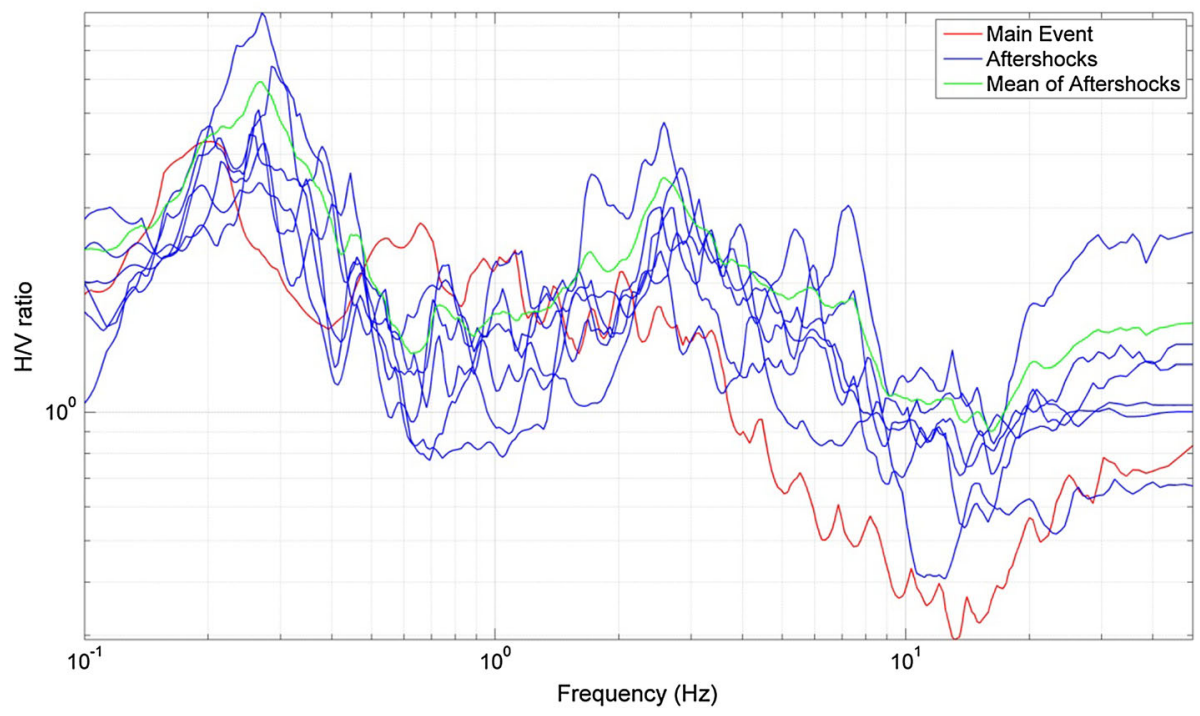

Fig. $8 \mathrm{H} / \mathrm{V}$ ratio of strong motion recordings at Kathmandu

\subsection{Determination of $\kappa$ and $\Delta \sigma$}

The strong motion record during an event contains the information regarding the source and site characteristics. Thus, the regional site parameters like kappa $(\kappa)$ and stress drop $(\Delta \sigma)$ can be derived by calibrating the model with the recorded data at Kathmandu. From Eq. 8 it can be observed that Fourier amplitude depends linearly on $\kappa$ in logarithmic scale. Hence, $\kappa$ could be determined from the slope of the best-fit line to the Fourier spectra with frequency in log-linear scale (Raghukanth and Somala 2009). As kappa ( $\kappa)$ influences the high frequency amplitude, the straight-line need to be fitted only on the high frequency range $(>5 \mathrm{~Hz})$ of the spectra. Following this procedure, $\kappa$ for the horizontal component $\left(\kappa_{h}\right)$ and vertical component $\left(\kappa_{v}\right)$ for the main event is obtained as 0.034 and 0.032 respectively. Similarly, $\kappa$ is obtained for aftershocks and is given in Table 4. The average $\kappa_{h}$ and $\kappa_{v}$ for the region is estimated to be $0.032( \pm 0.0019)$ and $0.029( \pm 0.0019)$ respectively. It can be seen that $\kappa_{h}$ is slightly greater than $\kappa_{v}$ indicating site amplification. Chandler et al. (2006) has developed an empirical equation between shear wave velocity in the top $30 \mathrm{~m}\left(\mathrm{~V}_{\mathrm{s} 30}\right)$ and $\kappa$. On substituting the obtained $\kappa$ value (0.032) in the empirical equation, give $\mathrm{V}_{\mathrm{s} 30}$ to be $1.12 \mathrm{~km} / \mathrm{s}$. Thus it is clear that region is categorized under B-type soil condition $\left(0.76 \mathrm{~km} / \mathrm{s}<\mathrm{V}_{\mathrm{s} 30} \leq 1.5 \mathrm{~km} / \mathrm{s}\right)$ (IBC 2009). The parameter $\Delta \sigma$ is then found out by minimizing mean square error between the observed response spectra $\left(O_{i}\right)$ and response spectra obtained from the recorded data $\left(S_{i}\right)$ for $5 \%$ damping. The mean square error $\left(\varepsilon^{2}\right)$ estimated at all frequency points $\left(N_{f}\right)$ can be expressed as:

$$
\varepsilon^{2}=\sum_{i=1}^{N_{f}}\left[\log \left(O_{i}\right)-\log \left(S_{i}\right)\right]^{2} .
$$

If a closed form equation for $\varepsilon^{2}$ as a function of $\Delta \sigma$ is available, the general approach is to differentiate the equation with respect to stress drop and solve it by equating to zero. Such 
Table 4 Kappa and stress drop for the main-event and aftershocks

\begin{tabular}{|c|c|c|c|c|c|c|}
\hline \multirow{2}{*}{ Magnitude $\left(\mathrm{M}_{\mathrm{w}}\right)$} & \multirow[t]{2}{*}{ Date of event } & \multicolumn{2}{|l|}{ Epicenter } & \multicolumn{2}{|l|}{ Kappa } & \multirow{2}{*}{$\begin{array}{l}\text { Stress drop }(\Delta \sigma) \\
\text { (bars) }\end{array}$} \\
\hline & & $\begin{array}{l}\text { Latitude } \\
\left({ }^{\circ} \mathrm{N}\right)\end{array}$ & $\begin{array}{l}\text { Longitude } \\
\left({ }^{\circ} \mathrm{E}\right)\end{array}$ & $\kappa_{\mathrm{h}}$ & $\kappa_{\mathrm{v}}$ & \\
\hline 7.86 & 25-April-2015 & 28.15 & 84.71 & 0.034 & 0.032 & 74 \\
\hline 7.3 & 12-May-2015 & 27.84 & 86.08 & 0.034 & 0.031 & 80 \\
\hline 6.7 & 26-April-2015 & 27.78 & 86 & 0.031 & 0.028 & 95 \\
\hline 5.6 & 25-April-2015 & 27.81 & 84.87 & 0.029 & 0.027 & 55 \\
\hline 5.5 & 25-April-2015 & 27.91 & 85.65 & 0.032 & 0.029 & 50 \\
\hline 5.3 & 26-April-2015 & 27.76 & 85.77 & 0.033 & 0.028 & 69 \\
\hline
\end{tabular}

a closed form analytical expression is difficult to formulate. Hence, the mean square error is estimated numerically for wide range of stress drop (10-1000 bars). The obtained optimum stress drop for main event is 74 bars. The stress drop values for aftershocks are also estimated by error minimization between corresponding recorded and simulated response spectra. The obtained stress drop values for main-event and aftershocks are reported in Table 4. Kayal (2008) has reported the stress drop range for Himalayan faults as 50-200 bars. It can be observed that the obtained $\Delta \sigma$ values are also within this range. The comparison of observed response spectra and the response spectra obtained from the recorded data for $5 \%$ damping for the main-event event and aftershocks are shown in Fig. 9. It can be observed that the simulated response spectras are comparable with the response spectras obtained from recorded data. The good comparison of response spectras indicates that the seismological model is able to capture the frequency content of the ground motion effectively. Hence, this model can be suitably used to simulate ground motions at various stations in the epicentral region.

\subsection{Simulation of ground accelerations}

The seismological model with the input parameters summarized in Table 5 is used to simulate the acceleration time histories. The $\mathrm{V}_{\mathrm{s} 30}$ distribution for Nepal-Himalayan region suggests that the region is mostly in B-type soil condition (http://earthquake.usgs. gov/hazards/apps/vs30/). Hence, the simulations in the present study are performed for B-type soil condition. The H/V ratio obtained at Kathmandu is used as $A(f)$ for all the simulations. Similarity in the soil type (B-type) of the recording station with that at Himalayan region, supports this claim of using same $\mathrm{H} / \mathrm{V}$ ratio for other stations in the region. Acceleration time histories are simulated at some important stations where the effect of the earthquake is felt and the damages are reported. These station locations and corresponding MMI values are given in Table 6. It can be observed from Table 6. that the PGA values for the stations near epicenter $(<150 \mathrm{~km})$ like Kathmandu, Patan, Bharathpur, Lamjung, Pokhara are obtained as 0.153, 0.148, 0.075, 0.058, $0.034 \mathrm{~g}$ respectively. Whereas for stations which are far from epicenter like Delhi, Sulthanpur, Nizamabad has PGA in the order of $0.001,0.002$ and $0.007 \mathrm{~g}$ respectively. From this, it is clear that the PGA values near the epicentral region are distributed more unevenly than that for far stations. Thus to understand this spatial variability better, the ground motions are simulated on a grid near the epicentral region. The size of grid is taken as 


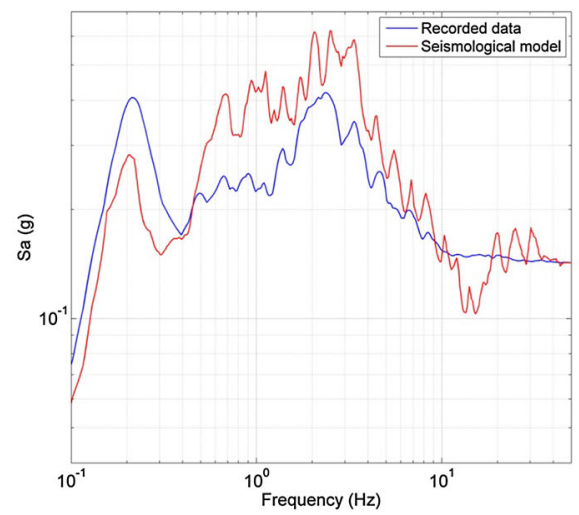

(a) Main event $M_{w}-7.86$

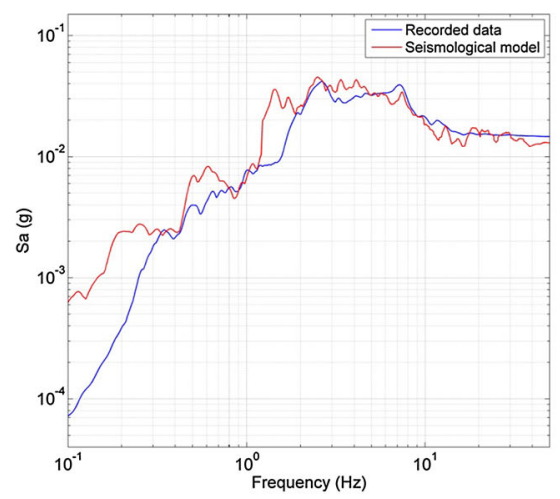

(c) Aftershock $M_{w}-6.7$

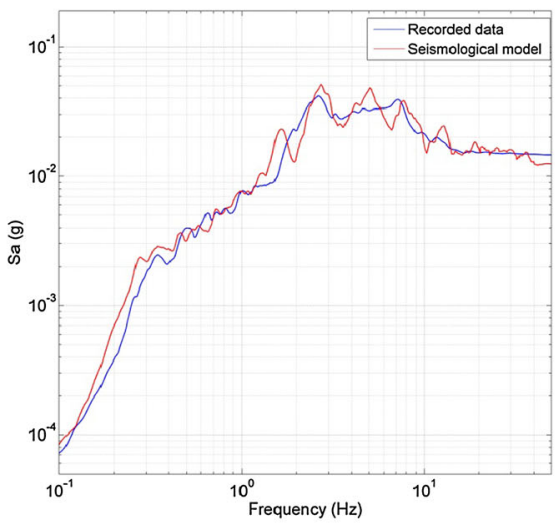

(e) Aftershock $M_{w}-5.5$

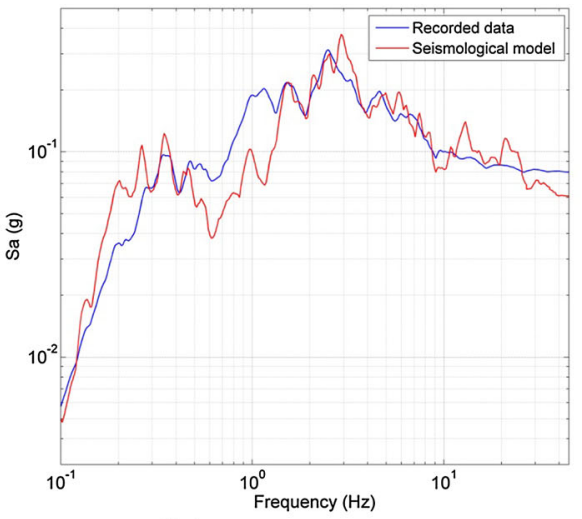

(b) Aftershock $\mathbf{M}_{\mathbf{w}}-7.3$

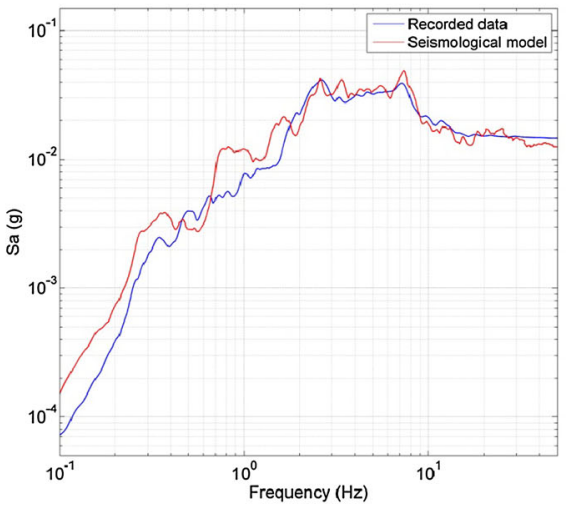

(d) Aftershock $M_{w}-5.6$

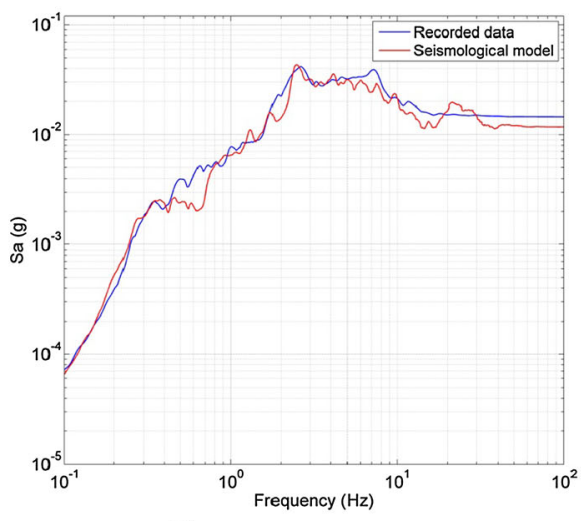

(f) Aftershock $M_{w}-5.3$

Fig. 9 Comparison between recorded and stochastic finite fault seismological model- simulated response spectra 
Table 5 Input parameters for the stochastic finite fault seismological model

\begin{tabular}{lll}
\hline Parameters & \multicolumn{2}{l}{ Nepal earthquake } \\
\cline { 2 - 3 } & Main event & Aftershock \\
\hline Magnitude, $\mathrm{M}_{\mathrm{w}}$ & 7.86 & 7.3 \\
Location & & \\
Latitude $\left({ }^{\circ} \mathrm{N}\right)$ & 28.147 & 27.837 \\
Longitude $\left({ }^{\circ} \mathrm{E}\right)$ & 84.708 & 86.077 \\
Depth to the top of the fault $(\mathrm{km})$ & 0.67 & 8.59 \\
Stress drop (bars) & 74 & 80 \\
Quality factor, $Q(f)($ Singh et al. 2004) & $253 f^{0.8}$ & $253 f^{0.8}$ \\
Fault dimensions $(\mathrm{km})$ & $220 \times 165$ & $125 \times 81.9$ \\
Sub-fault dimensions $(\mathrm{km})$ & $20 \times 15$ & $5 \times 3.9$ \\
Fault orientation & & \\
Strike $\left({ }^{\circ}\right)$ & 295 & 305 \\
Dip $\left({ }^{\circ}\right)$ & 10 & 9 \\
Pulsing area percentage & 50 & 50 \\
Rupture velocity & $0.8 \mathrm{~V}_{\mathrm{s}}$ & $0.8 \mathrm{~V}_{\mathrm{s}}$ \\
Slip distribution & USGS & USGS \\
\hline
\end{tabular}

$320 \times 280 \mathrm{~km}$ with a grid-point spacing of $4 \mathrm{~km}$. The obtained PGA on this grid is represented by contour plot as shown in Fig. 10. It can be observed that the PGA contour plots exhibit high variability near the epicentral region. Concurrently, when distance from the epicenter increases, the contour becomes axis-symmetric. The spatial variability near the epicentral region is attributed to the finiteness of source characteristics. The maximum PGA of $0.3 \mathrm{~g}$ is observed at approximately $60 \mathrm{~km}$ east of the epicentral region where the maximum slip is observed.

The structures are selectively excited during an earthquake, depending on the period of ground motion and natural time period of the structure. The rigid structures are more sensitive to short period while the flexible structures to long period waves. IBC 2009 has identified 0.2 and $1 \mathrm{~s}$ time period as short and long periods respectively. The simulated Sa contour for $0.2 \mathrm{~s}$ and $1 \mathrm{~s}$ time period for the event is presented in Fig. 11a, b respectively. It can be observed that Sa contour pattern is similar to the PGA contour obtained in Fig. 10. The maximum value of spectral acceleration ( $\mathrm{Sa}$ ) is observed to be $0.59 \mathrm{~g}$ for time period $0.2 \mathrm{~s}$ and $0.3 \mathrm{~g}$ for time period $1 \mathrm{~s}$, both on east side of the epicenter. Stations such as Rasuwa, Kodari, Dhading, Bidur and Nuwakot are observed to have high Sa value $(>0.45 \mathrm{~g}$ for time period $0.2 \mathrm{~s}$ and $>0.2 \mathrm{~g}$ for time period $1 \mathrm{~s})$.

\section{PGA from MMI data}

The previous section explained the application of stochastic finite fault seismological model to estimate PGA values. Another approach to estimate ground motion characteristics is through damage reports. There are various media reports, field investigations and databases, projecting the damages at various places during the event. The MMI values are assigned based on the intensity of these damage reports. In present study, the MMI values are fixed based on various media reports and the values reported by USGS (http:// 
Table 6 Comparison among various PGA estimate

\begin{tabular}{|c|c|c|c|c|c|c|c|}
\hline Station & $\begin{array}{l}\text { Latitude } \\
\left({ }^{\circ} \mathrm{N}\right)\end{array}$ & $\begin{array}{l}\text { Longitude } \\
\left({ }^{\circ} \mathrm{E}\right)\end{array}$ & $\begin{array}{l}\text { Epicentral } \\
\text { Distance }(\mathrm{km})\end{array}$ & MMI & Reference & $\begin{array}{l}\text { MMI- } \\
\text { PGA (g) }\end{array}$ & $\begin{array}{l}\text { PGA } \\
\text { (g) } \\
\text { Stoch. } \\
\text { fault }\end{array}$ \\
\hline Kirtipur & 27.68 & 85.28 & 76.57 & VIII & e.kantipur.com & 0.249 & 0.165 \\
\hline Kathmandu & 27.70 & 85.33 & 78.93 & VIII & $\begin{array}{l}\text { NDTV, The } \\
\text { Indian express }\end{array}$ & 0.249 & 0.153 \\
\hline Patan & 27.67 & 85.32 & 80.24 & VIII & $\mathrm{BBC}$ & 0.249 & 0.148 \\
\hline Banepa & 27.63 & 85.52 & 97.53 & VIII & Khaleej times & 0.249 & 0.150 \\
\hline Bharatpur & 27.68 & 84.43 & 58.65 & VIII & Anadolu agency & 0.249 & 0.075 \\
\hline Panauti & 27.58 & 85.52 & 101.00 & VIII & Library journal & 0.249 & 0.144 \\
\hline Kodari & 27.95 & 85.03 & 38.30 & VIII & e.kantipur.com & 0.249 & 0.241 \\
\hline Hitura & 27.42 & 85.03 & 88.11 & VII & $\begin{array}{l}\text { Earthquakes } \\
\text { today }\end{array}$ & 0.126 & 0.083 \\
\hline Janakpur & 26.73 & 85.93 & 198.40 & VII & NDTV & 0.126 & 0.033 \\
\hline Lamjung & 28.28 & 84.35 & 38.42 & VI & Edinburgh news & 0.064 & 0.058 \\
\hline Pokhara & 28.26 & 83.97 & 74.62 & VI & $\mathrm{BBC}$ & 0.064 & 0.034 \\
\hline Muzaffarpur & 26.12 & 85.40 & 236.87 & VI & NDTV & 0.064 & 0.022 \\
\hline Gorakhpur & 26.76 & 83.37 & 205.23 & $\mathrm{~V}$ & $\begin{array}{l}\text { The indian } \\
\text { express }\end{array}$ & 0.033 & 0.016 \\
\hline Bansi & 27.18 & 82.93 & 207.66 & V & Financial express & 0.033 & 0.016 \\
\hline Dhankuta & 26.98 & 87.33 & 287.49 & V & e.kantipur.com & 0.033 & 0.0121 \\
\hline Patna & 25.60 & 85.10 & 287.62 & V & $\begin{array}{l}\text { The economics } \\
\text { times }\end{array}$ & 0.033 & 0.015 \\
\hline Ayodhya & 26.80 & 82.20 & 290.39 & V & India times & 0.033 & 0.009 \\
\hline Nizamabad & 27.92 & 79.07 & 554.66 & IV & f.india & 0.017 & 0.002 \\
\hline Delhi & 28.61 & 77.23 & 736.29 & IV & indread.com & 0.017 & 0.001 \\
\hline Sultanpur & 26.25 & 82.00 & 341.65 & IV & Hans india & 0.017 & 0.007 \\
\hline
\end{tabular}

earthquake.usgs.gov/earthquakes/eventpage/us20002926\#impact_pager). The estimated MMI values at few stations are given in Table 6. A severe damage index of VIII is observed for regions like Kathmandu, Bhakthapur, Patan. The simulated PGA values at these stations are greater than $0.15 \mathrm{~g}$. While for stations like Bhakthapur though the intensity is severe (VIII) the simulated PGA value is $0.075 \mathrm{~g}$. This difference may be attributed to the local site condition and damages at surface level. It will be interesting to estimate PGA from these damage intensities, as there is no other data available to check the consistency of the simulated PGAs. In the present study, the empirical equation given by Iyengar and Raghukanth (2003) for Indian conditions is used. The linear relation between In (PGA) and MMI reported by Iyengar and Raghukanth (2003) comparing Indian MMI and instrumental PGA data with the help of 43 sample values is expressed as:

$$
\ln (P G A / g)=0.6782 \mathrm{MMI}-6.8163 ; \quad \sigma \ln (\varepsilon)=0.7311
$$

PGA values estimated from empirical equation (Eq. 10) and seismological model at few stations are summarised in Table 6. It is clear that the PGA values near the epicentral 


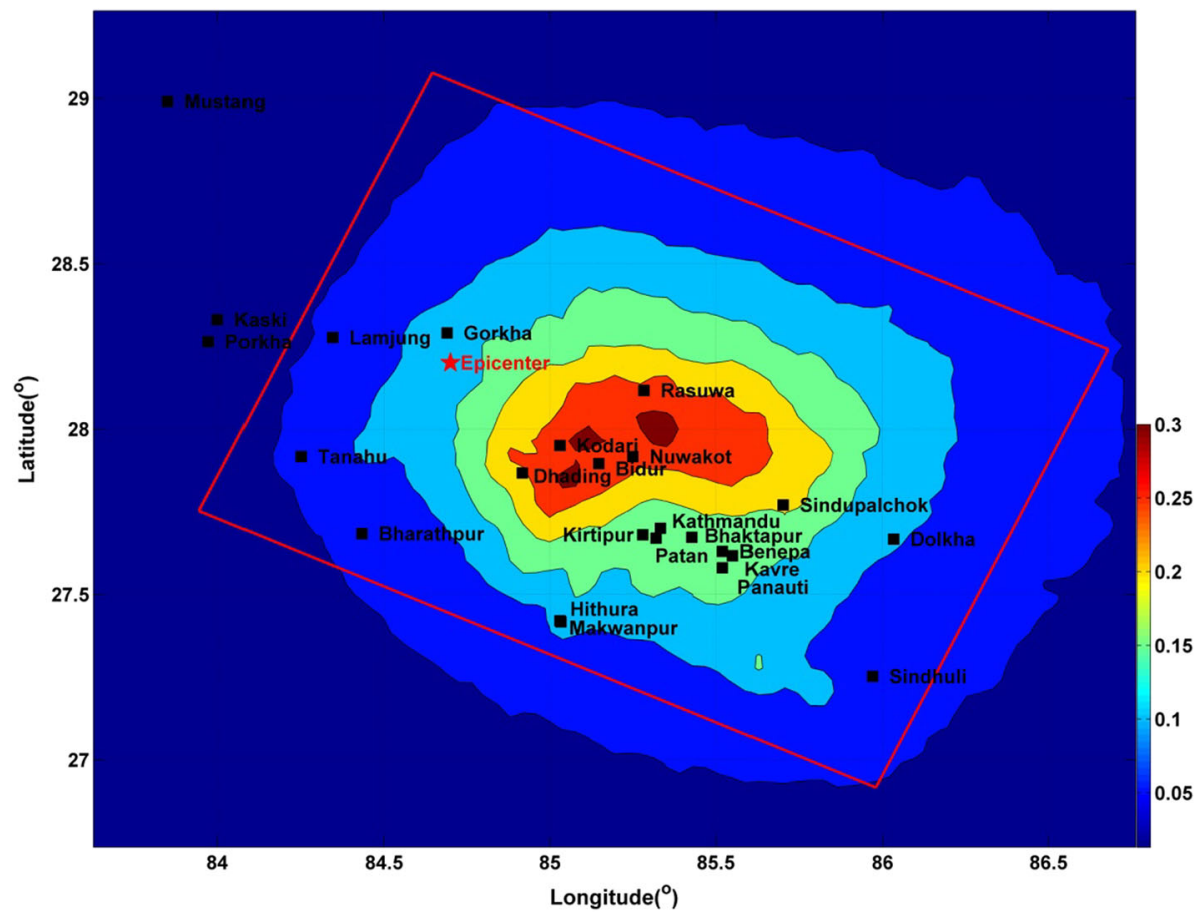

Fig. 10 Simulated PGA (g) on B-type sites near the epicentral region. The rectangular box indicate the surface projection of the fault plane

region are in agreement with each other whereas, considerable scatter are observed at far stations. To understand this variation better, the attenuation of PGA value with epicentral distance for more number of stations are obtained from both, simulation and empirical relation, and illustrated in Fig. 12. From the Fig. 12, it is evident that near the epicentral region the simulated results at B-type are in agreement with the PGA values from damage reports. The slight variations in results near the epicentral region are due local site conditions and quality of construction practices. It can be noted that at far stations, PGA values from the simulations are significantly low when compared to that from empirical equation. This variation noticed is because most of these stations lie in IndoGangetic plain. Indo-Gangetic plain has alluvial deposition varying from $1 \mathrm{~km}$ in the south to $6 \mathrm{~km}$ in the north (Geological Survey of India 2000). For this region, the amplification PGA is reported to be up to 2-4 respectively (Saikat and Raghukanth 2014; Srinagesh et al. 2011). Thus, it is very evident that the plain constitute of C or D type soil condition. Thus, the simulated results at B-Type soil condition should be modified to consider the soil amplification at far of stations. In the present study, comparing the PGA values from simulations and empirical equations, the average amplification observed in the Indo-Gangetic plain is of the order of $2-6$, which is in agreement with that reported by Srinagesh et al. (2011). 


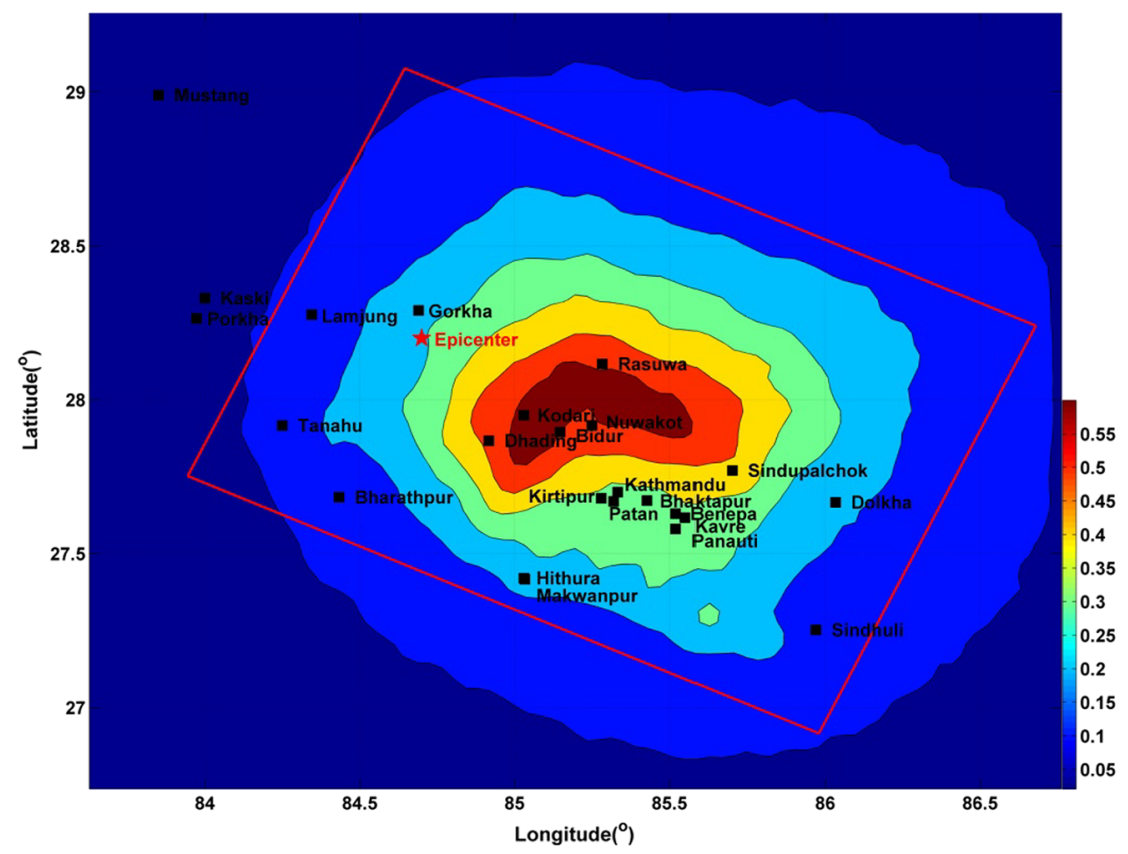

(a)

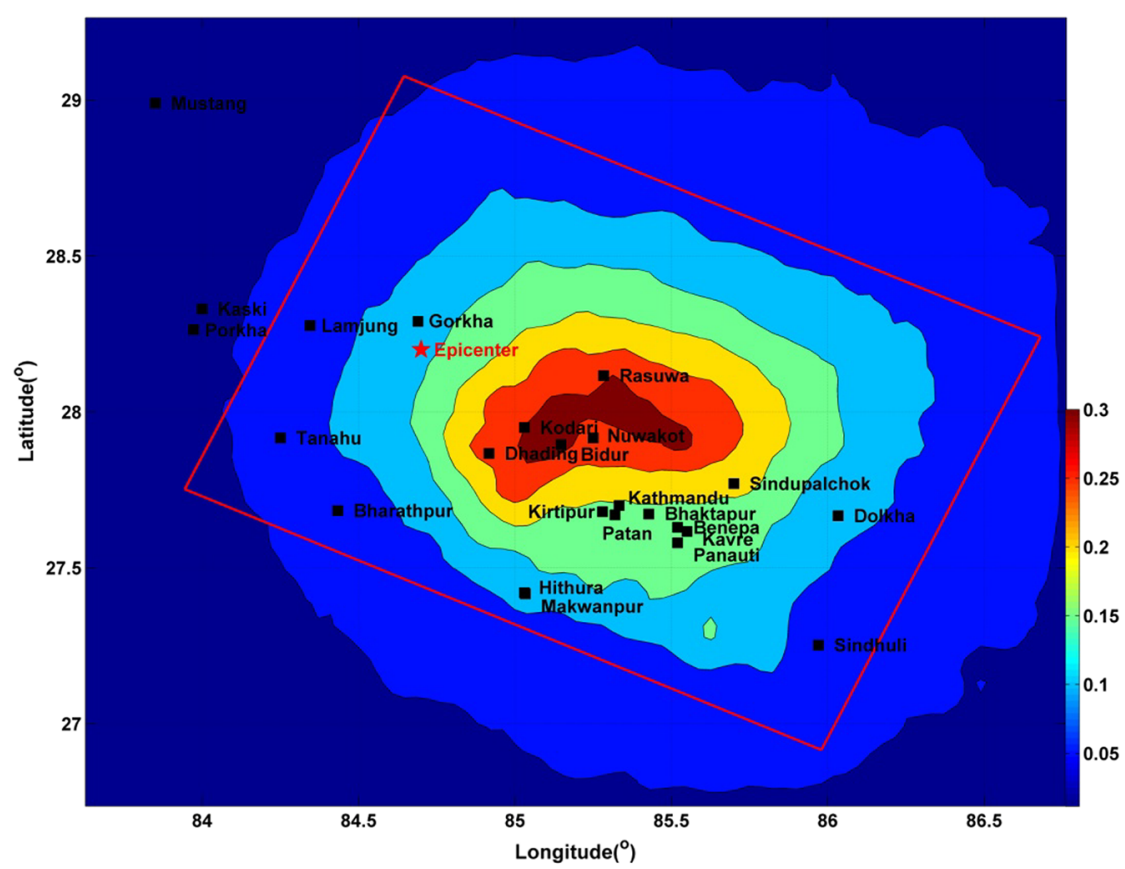

(b)

Fig. 11 Spectral acceleration $(\mathrm{g})$ a short period at $\mathrm{T}=0.2 \mathrm{~s} \mathbf{b}$ long period at $\mathrm{T}=1 \mathrm{~s}$, near the epicentral region 


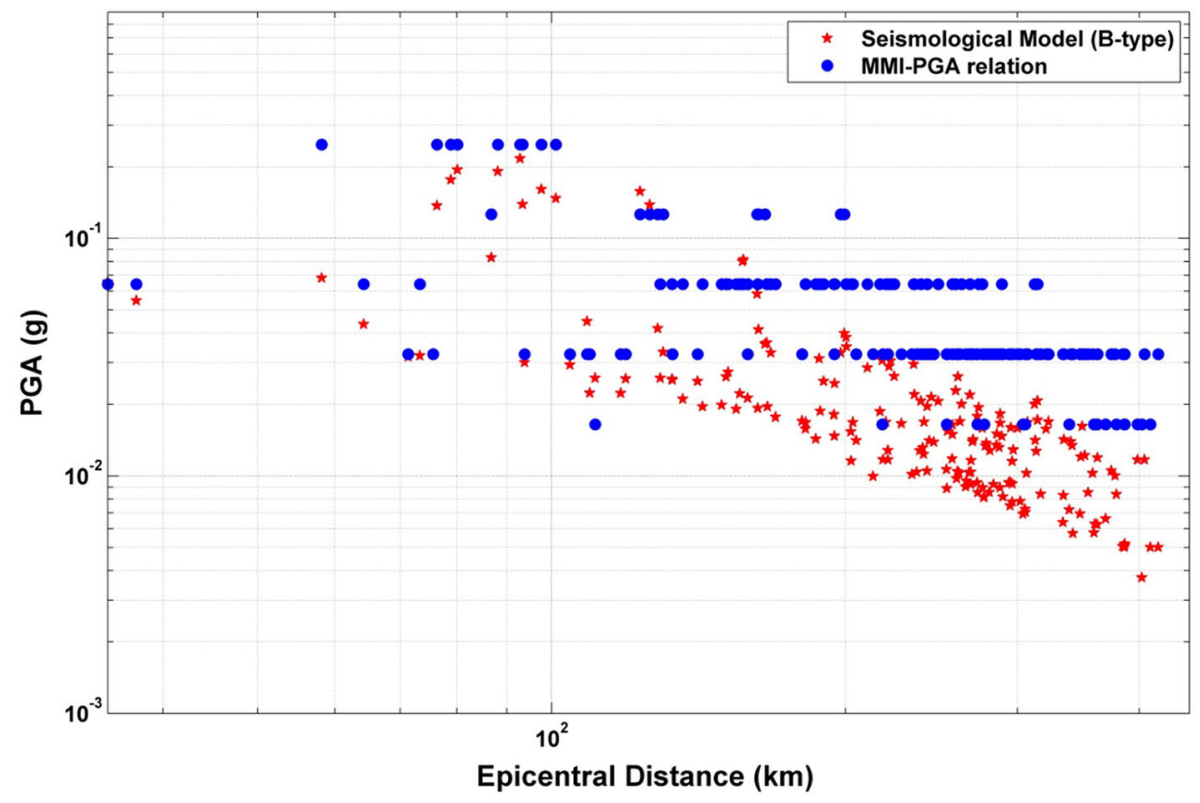

Fig. 12 PGA versus epicentral distance; comparison between the PGA value obtained from stochastic finite fault seismological model at B-Type with that obtained from PGA-MMI empirical equation

\section{Summary and conclusions}

In this article, ground motion during the Nepal (2015) earthquake is estimated near the epicentral region. Strong motion recording for the event is available only at Kathmandu city. In the absence of recorded data, source mechanism and stochastic seismological model is used to generate large samples of artificial ground motion time histories. First, SPECFEM is used to simulate low frequency displacement time histories. The simulations is performed using slip distribution given in Fig. 2 as source and regional velocity profile given in Table 2 as material property distribution with respect to depth in the region. The effect of topography on ground motion is evaluated by simulating both with and without topography. It is clear from Fig. 4 that the simulated displacement time history with topography matches with the recorded data than that without topography. Displacement time histories simulated with topography at various stations and contour maps of PGD and GRD are obtained as shown in Figs. 6 and 7 respectively. The simulated ground motions in this study bring out the directivity effects due to fault orientation and rupture direction. GRD contour maps indicate the permanent movement at the end of the earthquake shaking due to the effect of slip across the fault. As the numerical methods are not efficient in capturing high frequency ground motion of engineering interest, seismological model is employed to simulate acceleration time histories. In the study, stochastic finite fault seismological model (Boore 2009) is used to simulate acceleration time histories in the epicentral region. The simulation of ground motions by seismological model depends on region specific parameters such as stress drop, slip distribution, orientation of fault plane, focal depth, site amplification function, kappa factor and quality factor. The quality factor and geometric attenuation for the region is taken from the past literature of Singh et al. 
(2004). Site amplification at Kathmandu is estimated from the ratio of the horizontal to vertical response spectra shown in Fig. 8. The high frequency attenuation parameter kappa is estimated from the slope of Fourier spectra in log-linear scale. The average kappa in horizontal and vertical direction is obtained as $0.032( \pm 0.0019)$ and $0.029( \pm 0.0019)$ respectively. The higher value of kappa in horizontal compared to vertical direction indicates site amplification. The stress drop is determined by minimizing the mean square error between the observed and simulated response spectra. Figure 9a shows the comparison between the simulated and recorded response spectra for the main event. The obtained stress drop for the main event and aftershocks lies in between 50 and 95 bars and is observed to be consistent with the estimates from past events in the Himalayan region. The calibrated seismological model is further used to estimate the ground motion at various stations in the epicentral region. The simulated results are valid for the B- type soil condition. The obtained results are presented in the form of contours maps of peak ground acceleration (PGA) (Fig. 10). The maximum PGA values observed to the east of the epicenter are attributed to the finiteness of the source. Spectral acceleration at time period 0.2 and $1 \mathrm{~s}$ are shown in Fig. 11(a, b) respectively. This Sa contours give an insight to the damage potential of rigid and flexible structures respectively. Another approach for assessing the seismological model is through MMI-PGA empirical equations. The comparison of PGA values from two estimates at specific stations is shown in Table 6 and the attenuation of PGA with respect to epicentral distance is illustrated in Fig. 11. It can be seen that the PGA values from both the approaches are consistent with each other. The high damage index from most of the far stations, which lies on Indo-Gangetic plain, is due to the amplification of wave on traversing through the sedimentary deposits in the region. The average amplification is of the order of 2-6 for Indo-Gangetic plain.

From the study it is clear that poor constructional practices have increased the vulnerability in the region. Since there is no strong motion data available, the simulated ground motion aids in assessing the ground parameters like amplitude, frequency content etc. which caused the damage. The ground motion contours obtained in this study can be used to understand pattern and level of damage of the existing structures. The obtained displacement time histories can be used by engineers in displacement-based design of structures in the Himalayan region. The simulated contour maps of PGD and GRD can also be used as a basis for redesign of the public amenities like pipeline, railway lines etc. Thus, the simulated ground motion time histories provides an estimate for the future event of comparable magnitude in Himalayan region.

\section{References}

Atkinson GM, Assatourians K, Boore DM, Campbell K, Motazedian D (2009) A guide to differences between stochastic point-source and stochastic finite-fault simulations. Bull Seismol Soc Am 99(6):3192-3201

Bilham R, Gaur VK, Molnar P (2001) Himalayan seismic hazard. Science (Washington) 293(5534):1442-1444

Boore DM (2009) Comparing stochastic point-source and finite-source ground-motion simulations: SMSIM and EXSIM. Bull Seismol Soc Am 99:3202-3216

Boore DM, Boatwright J (1984) Average body-wave radiation coefficients. Bull Seismol Soc Am $74: 1615-1621$

Chandler AM, Lam NTK, Tsang HH (2006) Near-surface attenuation modelling based on rock shear-wave velocity profile. Soil Dyn Earthq Eng 26(11):1004-1014

Chitrakar GR, Pandey MR (1986) Historical earthquakes of Nepal. Bull Geol Soc Nepal 4:7-8 
Dunn JA, Auden JB, Ghosh AMN, Roy SC, Wadia DN (1939) The Bihar-Nepal earthquake of 1934, Mem. Geol Surv India 73:118-137

Field E, Jacob K (1993) The theoretical response of sedimentary layers to ambient seismic noise. Geophys Res Lett 20(24):2925-2928

GSI (2000) Seismotectonic Atlas of India and its environs. Geological Survey of India

IBC (2009) International building code. International Code Council, ICC

Iyengar RN, Raghukanth STG (2003) Attenuation of strong ground motion and site specific seismicity in Peninsular India. In: Proceedings of national seminar on seismic design of nuclear power plants, SERC, Chennai (Delhi: Allied Publishers Pvt. Ltd.), 21-22 February 2003, pp 269-291

Kayal JR (2008) Microearthquake seismology and seismotectonics of South Asia. Capital Publishing Company, New Delhi

Khattri KN (1987) Great earthquakes, seismicity gaps and potential for earthquake disaster along the Himalaya plate boundary. Tectonophysics 138(1):79-92

Komatitsch D, Tromp J (1999) Introduction to the spectral-element method for 3-D seismic wave propagation. Geophys J Int 139(3):806-822

Komatitsch D, Vilotte JP, Tromp J, and development team (2015) SPECFEM 3D cartesian user manual version 3. Pirnceton University, CNRS, University of Marseille and ETH Zürich

Lavé J, Yule D, Sapkota S, Basant K, Madden C, Attal M, Pandey R (2005) Evidence for a great Medieval earthquake ( 1100 A.D.) in the central Himalayas. Nepal Sci 307(5713):1302-1305

Motazedian D, Atkinson GM (2005) Stochastic finite-fault modeling based on a dynamic corner frequency. Bull Seismol Soc Am 95(3):995-1010

Nakamura Y (1989) A method for dynamic characteristics estimation of subsurface using microtremor on the ground surface. Railw Tech Res Inst, Q Rep 30(1):25-33

NDMA (2011) Development of probabilistic seismic hazard map of India, a technical report of the working committee of experts (WCE) constituted by the National Disaster Management Authority (NDMA). Government of India, New Delhi

Patera AT (1984) A spectral element method for fluid dynamics: laminar flow in a channel expansion. J Comput Phys 54(3):468-488

Paudyal YR, Yatabe R, Bhandary NP, Dahal RK (2013) Basement topography of the Kathmandu Basin using microtremor observation. J Asian Earth Sci 62:627-637

Raghukanth STG, Somala SN (2009) Modeling of strong motion data in Northeastern India: Q, stress drop and site amplification. Bull Seismol Soc Am 99:705-725

Raghukanth STG, Lakshmi Kumari K, Kavitha B (2012) Estimation of ground motion during the 18th September 2011 Sikkim earthquake. Geomat Nat Hazards Risk 3(1):9-34

Saikat B, Raghukanth STG (2014) Effect of Indo-Gangetic plain on ground motion. In: Proceedings of the 5th Asia conference of earthquake engineering, Taipei, Taiwan, 16-18 October 2014

Singh SK, Garcia D, Pacheco JF, Valenzuela R, Bansal BK, Dattatrayam RS (2004) Q of the Indian Shield. Bull Seismol Soc Am 94(4):1564-1570

Srinagesh D, Singh SK, Chadha RK, Paul A, Suresh G, Ordaz M, Dattatrayam RS (2011) Amplification of seismic waves in the central Indo-Gangetic basin, India. Bull Seismol Soc Am 101(5):2231-2242

Upreti BN (1999) An overview of the stratigraphy and tectonics of the Nepal Himalaya. J Asian Earth Sci 17(5):577-606

Wald DJ, Quitoriano V, Heaton TH, Kanamori H (1999) Relationships between peak ground acceleration, peak ground velocity, and modified Mercalli intensity in California. Earthq Spectra 15(3):557-564

Yu G, Khattri KN, Anderson JG, Brune JN, Zeng Y (1995) Strong ground motion from the Uttarkashi, Himalaya, India, earthquake: comparison of observations with synthetics using the composite source model. Bull Seismol Soc Am 85(1):31-50 